\title{
Immune and Inflammatory Cell Composition of Human Lung Cancer Stroma
}

\author{
G-Andre Banat ${ }^{1}$, Aleksandra Tretyn ${ }^{2}$, Soni Savai Pullamsetti ${ }^{1,2}$, Jochen Wilhelm ${ }^{1}$, \\ Andreas Weigert ${ }^{3}$, Catherine Olesch ${ }^{3}$, Katharina Ebel ${ }^{2}$, Thorsten Stiewe ${ }^{4}$, \\ Friedrich Grimminger ${ }^{1}$, Werner Seeger ${ }^{1,2}$, Ludger Fink ${ }^{5}$, Rajkumar Savai ${ }^{1,2}{ }^{*}$
}

1 Internal Medicine, University of Giessen and Marburg Lung Center, Member of the German Center for Lung Research, Giessen, Germany, 2 Department of Lung Development and Remodeling, Max-PlanckInstitute for Heart and Lung Research, Member of the German Center for Lung Research, Bad Nauheim, Germany, 3 Institute of Biochemistry I, Goethe-University Frankfurt, Frankfurt, Germany, 4 Molecular Oncology, Philipps-University, Member of the German Center for Lung Research, Marburg, Germany, 5 Institute of Pathology and Cytology, UEGP, Wetzlar, Germany

* rajkumar.savai@mpi-bn.mpg.de

\section{Abstract}

\section{G openaccess}

Citation: Banat G-A, Tretyn A, Pullamsetti SS, Wilhelm J, Weigert A, Olesch C, et al. (2015) Immune and Inflammatory Cell Composition of Human Lung Cancer Stroma. PLoS ONE 10(9): e0139073. doi:10.1371/journal.pone.0139073

Editor: Gernot Zissel, Universitatsklinikum Freiburg, GERMANY

Received: February 3, 2015

Accepted: September 9, 2015

Published: September 28, 2015

Copyright: @ 2015 Banat et al. This is an open access article distributed under the terms of the Creative Commons Attribution License, which permits unrestricted use, distribution, and reproduction in any medium, provided the original author and source are credited.

Data Availability Statement: The authors mostly used commercially available lung cancer tissue array. LUC1501 contains 150 cores from normal/benign (3 cases) and cancer (70 cases with grading and TNM staging data), duplicated cores per case were purchased from Pantomics, Inc. (Cat no. LUC 1501; Richmond, CA, USA). Six additional samples of donor lung tissue were taken from lungs that were not transplanted. The study protocol for tissue donation was approved by the ethics committee ("Ethik Kommission am Fachbereich Humanmedizin der Justus Liebig Universität Giessen"). The tissue bank committee officer is Prof. Werner Seeger email:
Recent studies indicate that the abnormal microenvironment of tumors may play a critical role in carcinogenesis, including lung cancer. We comprehensively assessed the number of stromal cells, especially immune/inflammatory cells, in lung cancer and evaluated their infiltration in cancers of different stages, types and metastatic characteristics potential. Immunohistochemical analysis of lung cancer tissue arrays containing normal and lung cancer sections was performed. This analysis was combined with cyto-/histomorphological assessment and quantification of cells to classify/subclassify tumors accurately and to perform a high throughput analysis of stromal cell composition in different types of lung cancer. In human lung cancer sections we observed a significant elevation/infiltration of total-T lymphocytes $\left(\mathrm{CD}^{+}\right)$, cytotoxic-T cells $\left(\mathrm{CD} 8^{+}\right)$, T-helper cells $\left(\mathrm{CD} 4^{+}\right)$, B cells $\left(\mathrm{CD} 2 \mathrm{O}^{+}\right)$, macrophages $\left(\mathrm{CD}^{+} 8^{+}\right)$, mast cells $\left(\mathrm{CD} 117^{+}\right)$, mononuclear cells $\left(\mathrm{CD} 11 \mathrm{c}^{+}\right)$, plasma cells, activated-T cells $\left(\mathrm{MUM1}^{+}\right), \mathrm{B}$ cells, myeloid cells $\left(\mathrm{PD} 1^{+}\right)$and neutrophilic granulocytes (myeloperoxidase ${ }^{+}$) compared with healthy donor specimens. We observed all of these immune cell markers in different types of lung cancers including squamous cell carcinoma, adenocarcinoma, adenosquamous cell carcinoma, small cell carcinoma, papillary adenocarcinoma, metastatic adenocarcinoma, and bronchioloalveolar carcinoma. The numbers of all tumor-associated immune cells (except MUM1 ${ }^{+}$cells) in stage III cancer specimens was significantly greater than those in stage I samples. We observed substantial stage-dependent immune cell infiltration in human lung tumors suggesting that the tumor microenvironment plays a critical role during lung carcinogenesis. Strategies for therapeutic interference with lung cancer microenvironment should consider the complexity of its immune cell composition.

\section{Introduction}

Lung cancer is a highly aggressive and challenging disease and is the leading cause of cancer mortality worldwide. Despite ongoing therapeutic efforts, lung cancer patients have a poor 
Werner.Seeger@innere.med.uni-giessen.de.The additional 6 tissue samples are available upon request due to ethical restrictions.

Funding: This work was supported by Verein zur Förderung der Krebsforschung in Gießen e.V, and the LOEWE Universities of Giessen and Marburg Lung Center (UGMLC).

Competing Interests: The authors have declared that no competing interests exist. prognosis with an average 5-year survival rate of only $15 \%$ [1] [2]. Approximately $80-85 \%$ of all lung cancer patients are treated with one or more options within a standard regimen that involves surgery, radiation therapy, and chemotherapy with disease stage determining the therapeutic options. Although these treatments have produced promising results as neo-adjuvant and adjuvant strategies for early-stage patients and for treatment of locally advanced and advanced disease, treatment outcomes for lung cancer are still considered disappointing. This is largely due to a delay in diagnosis and inadequate knowledge about tumor progression and its associated molecular alterations [3]. Important advances have recently been made in identifying the molecular determinants of carcinogenesis, such as genetic alterations in many oncogenes (Kras, $c M y c, E G F R, A L K$, etc.) and tumor-suppressor genes ( $p 53, R A S S F 1, R B, F H I T$ ) [4, 5].

In addition to this genetic complexity, the cellular complexity of the tumor microenvironment is increasingly recognized as contributing directly to cancer initiation, progression and metastasis $[6,7]$. The tumor microenvironment, depending on the tumor location, is composed of stromal cells including fibroblasts, immune and inflammatory cells, adipocytes, glial cells, smooth muscle cells and resident and recruited vascular cells along with the extracellular matrix, growth factors/cytokines and other proteins that are locally and/or systemically produced. Although none of these stromal cells are tumorigenic, they may either stimulate or inhibit cancer cell proliferation/malignancy depending on the tumor microenvironment and the various interactions they may have with the cancer cells $[8,9]$.

Although immune cells should in principle detect and eliminate transformed cells, their interaction with tumor cells may lead to changes in their phenotype that may actually result in the establishment of a tumor-supporting environment in various cancer settings, including lung cancer [10-12]. Thus, a comprehensive analysis of the population/ composition of stromal cells and a better understanding of their impact on the process of carcinogenesis may eventually lead to improved anticancer therapies $[13,14]$. Along this line, there is now growing evidence that certain immune cells infiltrate into the tumors of human samples of lung cancer [12, 15-19]. However, to the best of our knowledge, the identification and quantification of several immune cell populations and their correlation to lung cancer type, stage and nodal status has not been reported. In this study, employing tissue arrays and immunohistochemistry, we substantially extended this characterization to include several immune cell populations as well as different lung cancer types, cancer stages, and tumor sizes as well as differences in nodal status. These techniques were combined with cyto-/histomorphological assessment and quantification of the cells, to classify/subclassify tumors accurately and high throughput analysis of stromal cell composition in different types of lung cancer.

\section{Materials and Methods}

\section{Lung Specimens}

Lung cancer tissue array, LUC1501 contains 150 cores from normal/benign ( 3 cases) and cancer (70 cases with grading and TNM staging data), duplicated cores per case were purchased from Pantomics, Inc. (Cat no. LUC 1501; Richmond, CA, USA). All the tissues were fixed in $10 \%$ neutral buffered formalin for 24 hours and processed using identical SOPs. Sections were picked onto Superfrost Plus or Startfrost adhesive slides. There may be $>5 \%$ core loss per slide but the core retention rate should be $>90 \%$. The tumor specimens were presented in duplicates for internal control and to assess tumor heterogeneity. In addition, a pathologist validated the tumors in the cores. The tumors cover between 50 and $100 \%$ of the cores. Six additional samples of donor lung tissue were taken from lungs that were not transplanted [20]. This donor lung tissue was non-transplanted lung tissue of transplant donors. The study protocol for tissue 
donation was approved by the ethics committee ("Ethik Kommission am Fachbereich Humanmedizin der Justus Liebig Universität Giessen") of the University Hospital Giessen (Giessen, Germany) in accordance with national law and with "Good Clinical Practice/International Conference on Harmonisation" guidelines. Written informed consent was obtained from each patient or the patient's next of kin (AZ 31/93) [20,21]. All specimens were analyzed under a Hamamatsu NDP slide scanner (Hamamatsu Nanozoomer 2.0HT) and its viewing platform (NDP.Viewer).

\section{Hematoxylin and Eosin Staining}

Lung cancer tissue array was deparaffinized in xylene followed by rehydration in $100 \%, 90 \%$, and $70 \%$ ethanol and distilled water. The slides were then incubated in fresh hematoxylin (Merck, Darmstadt, Germany) for 20 min and washed in distilled water, followed by incubation in acidified eosin solution (Sigma, Deisenhofen, Germany) for $1 \mathrm{~min}$ and washing. Finally, the slides were dehydrated in $90 \%$ and $100 \%$ ethanol, air dried, and mounted [20].

\section{Immunohistochemistry}

Immunohistochemical staining was performed using a Autostainer Plus (Dako, Hamburg, Germany) and mouse monoclonal antibodies from Dako, Medac (Hamburg, Germany), and Thermo Fisher (Dreieich, Germany) at dilutions shown in Table 1. A polyclonal antibody was only used for myeloperoxidase (MPO) staining. We followed the specific standardized protocol supplied by the manufacturer. Omission of the primary antibody served as a negative control. Briefly, slides were pretreated with Trilogy buffer (Medac; $1: 100,16 \mathrm{~min}$ at $95^{\circ} \mathrm{C}$ ), citrate low buffer (Thermo Fisher; $1: 100,26 \mathrm{~min}$ at $98^{\circ} \mathrm{C}$ ), or pronase $\mathrm{E}$ (Merck; $0.1 \%, 10 \mathrm{~min}$ at room temperature) followed by treatment with $3 \% \mathrm{H}_{2} \mathrm{O}_{2}$ for $8 \mathrm{~min}$. All antibodies were applied in a volume of $200 \mu \mathrm{l}$ and incubated for $30 \mathrm{~min}$. After washing (Medac wash buffer, 1:20 in aqua dest), secondary antibody (Medac) was applied in a volume of $200 \mu \mathrm{l}$ and incubated for $20 \mathrm{~min}$. After washing, each sample was incubated with polymer $(200 \mu \mathrm{l})$ for $30 \mathrm{~min}$ (note that the secondary antibody and polymer are components of the color-coded BrightVision HRP kit from Medac). The slides were washed twice and incubated in Bright DAB (Medac) for $10 \mathrm{~min}$. The slides were washed in aqua dest, counterstained with hematoxylin for $8 \mathrm{~min}$, and washed before coverslipping [20, 22].

\section{Data Analysis and Statistics}

The total number of cells and positively stained cells were counted in tissue sections. In combination with an immunohistochemical stain, we also relied on a cyto-/histomorphological

Table 1. Antibody details.

\begin{tabular}{lllll}
\hline Epitope & Clone & Dilution & Pretreatment \\
\hline CD3 & F.2.38 & $1: 400$ & Trilogy & Supplier \\
CD4 & 4B12 & $1: 1$ & Trilogy & Tako \\
CD8 & C8/144B & $1: 100$ & Trilogy & Medac \\
CD20 & L26 & $1: 1000$ & Citrate low \\
CD117/c-kit & C-kit & $1: 200$ & Citrate low \\
CD68 & PGM-1 & $1: 1000$ & Citrate low & Medac \\
CD11C & 5D11 & $1: 100$ & Trilogy & Dako \\
MUM-1 & Mum1p & $1: 100$ & Trilogy & Dako \\
PD-1 & MRQ22 & $1: 100$ & Trilogy & Medac \\
Myeloperoxidase & Polyclonal & $1: 2000$ & Pronase E \\
\hline
\end{tabular}

doi:10.1371/journal.pone.0139073.t001 
assessment of the cells by a pathologist. The H\&E stained TMA sections were assessed by pathologist for differentiating the tumor part from the non-tumor part The total number of cells and all the positively stained cells in tumor area of the core were counted. The values represent the cell count for each cell-type marker per 1000 total cells counted. The differences in these normalized counts between groups were estimated with a generalized linear model of the quasi-Poisson family with log-link. This model assumes that the response values follow a Poisson distribution, as is expected for counts. Analysis of the residuals indicated an overdispersion, that is, there was not a linear relationship between the mean and variance, a characteristic of purely Poisson-distributed data. This was accounted for by quasi-likelihood estimation of the Poisson model including an additional scale parameter [23]. Presented data are the predicted responses for the groups (means or expected values) with 95\% confidence intervals (CI). $\mathrm{P}$-values for the comparison of groups were also calculated for these models. Data from TNM classifications T2 and T3 were pooled for analysis. Data were analyzed with R version 3.1.0 [24, 25].

\section{Results}

\section{Histopathological Analysis of Lung Tumor Samples}

To characterize lung tumor morphology, human lung tumor microarrays were stained with hematoxylin and eosin. Fig 1 shows representative stained tissue specimens according to their pathology; healthy, squamous cell carcinoma, adenocarcinoma, adenosquamous carcinoma, small cell carcinoma, papillary adenocarcinoma, metastatic adenocarcinoma, and bronchioloalveolar carcinoma. All specimens were subjected to additional histopathological analysis.

\section{Analysis of the Tumor Microenvironment in Human Lung Cancer Tissues}

T lymphocytes. Infiltration of $\mathrm{T}$ lymphocytes into human lung tissue was assessed by immunohistochemical analysis using the $\mathrm{CD} 3$ antibody. We observed an increased number of $\mathrm{CD}^{+} \mathrm{T}$ cells in lung cancer [mean, 118 cells/per 1000 cells; 95\% CI, 105-133; here after mentioned as 118 (105...133)] compared with healthy donor lungs [28 (14 . .57); Fig 2A]. The infiltration of $\mathrm{CD}^{+} \mathrm{T}$ lymphocytes was independent of cancer type (Fig $2 \mathrm{~B}$ and $2 \mathrm{~F}$ ), but the number of infiltrating cells was higher in later stages of lung cancer $[173(151 \ldots 199)$ stage III vs. $61(33 . .114)$ stage I lung cancer, Fig $2 \mathrm{C}]$. The number of $\mathrm{CD}^{+} \mathrm{T}$ cells in tumor samples was independent of tumor size [T2: $119(104 \ldots 136]$ vs. T3: 88 (52 . 149)] and nodal status [N0: $123(106 \ldots 143)$ vs. N1+2: 101 (79. .130), Fig 2D and 2E] based on TNM staging.

To further evaluate the distribution of $\mathrm{T}$ lymphocyte subpopulations, sections were analyzed by immunostaining for the prevalence of $\mathrm{T}$ helper $\left(\mathrm{CD} 4^{+}\right)$and cytotoxic $\left(\mathrm{CD} 8^{+}\right) \mathrm{T}$ cells. As shown in Fig $3 \mathrm{~A}$, the number of $\mathrm{CD} 4^{+}$cells was significantly increased in tumor tissue compared with healthy donor tissue [62 (52 . .72) vs. 12 (4 . .32)]. The prevalence of T helper cells was independent of cancer type (Fig 3B and 3F), however the number of infiltrating cells was higher in stage III cancer compared with stage I [113 (102 . .125) vs. $22(12 \ldots 42)$, Fig 3C]. The number of $\mathrm{CD}^{+} \mathrm{T}$ lymphocytes in tumor samples was independent of tumor size [T2: 62 $(52 \ldots 75]$ vs. T3: $60(32 \ldots 114)]$ and nodal status [N0: 63 (51. . .77) vs. N1+2: $60(43 \ldots 83)$, Fig $3 \mathrm{D}$ and $3 \mathrm{E}]$. Similar results were obtained for infiltrating cytotoxic $\mathrm{T}$ lymphocytes, with a higher number of $\mathrm{CD}^{+}$cells in tumor tissues compared with healthy controls [80 (69. .93) vs. $17(7 \ldots 41)]$ and higher $\mathrm{CD} 8^{+}$cell infiltration in stage III vs. stage I lung cancer [132

$(114 \ldots 154)$ vs. 51 (27.. .98), Fig 4A and 4C]. There was no correlation between the prevalence of cytotoxic T cells and cancer type, tumor size or nodal status (Fig 4B, 4D and 4E). 
Macrophages and mast cells. Tumor-associated macrophages were assessed based on the expression of CD68. We observed an increased number of $\mathrm{CD}^{+} 8^{+}$cells in lung cancer [39 (30. . 49)] compared with healthy donor lungs [5 (1 . .34); Fig 5A]. The number of tumorassociated macrophages also correlated with cancer stage [stage III: $75(62 \ldots .92)$ vs. stage I: 9 (2...41), Fig 5C] and was independent of cancer type, tumor size, and nodal status (Fig 5B and $5 \mathrm{D}-5 \mathrm{~F})$.

Next, we assessed the number of mast cells in the tumor tissue based on CD117 (cKit) immunodetection. As shown in Fig 6A, the number of mast cells was higher in the tumor tissue compared with healthy donor tissue $[103(88 \ldots 122)$ vs. $11(2 \ldots 48)]$ and was substantially elevated in stage III cancer compared with stage I [183 (157...213) vs. $61(30 \ldots 124)$, Fig 6C]. We did not detect any differences among samples according to cancer type, tumor size or nodal status (Fig 6B and 6D-6F).

A

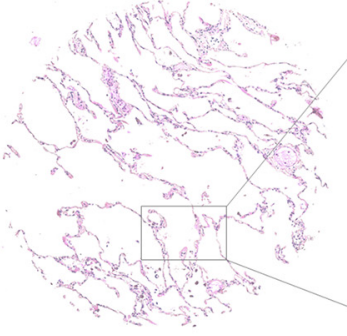

B

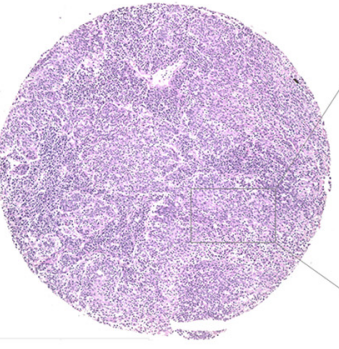

C

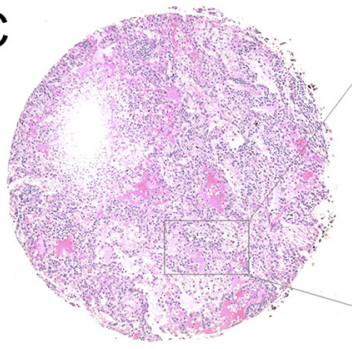

D
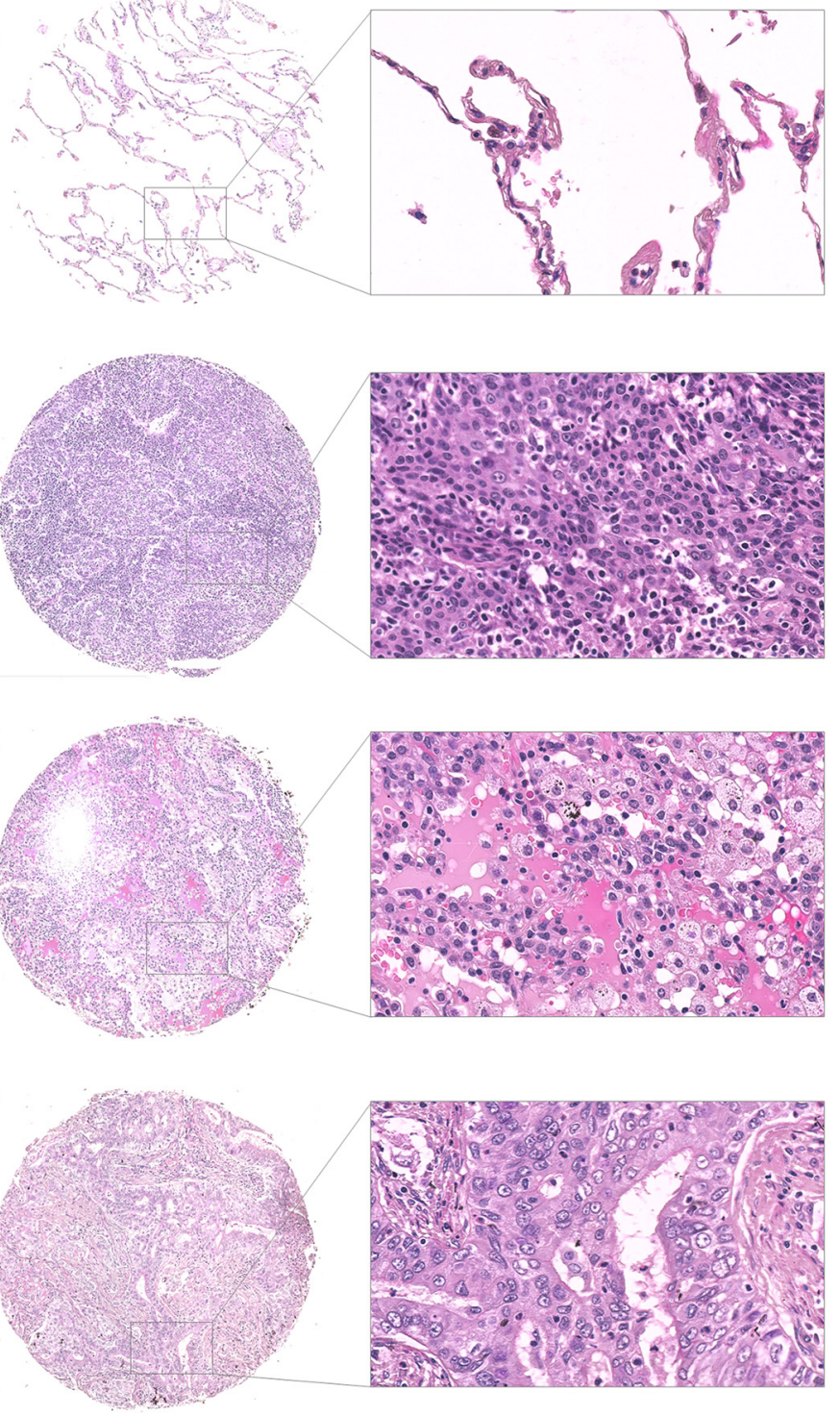

E

G

F
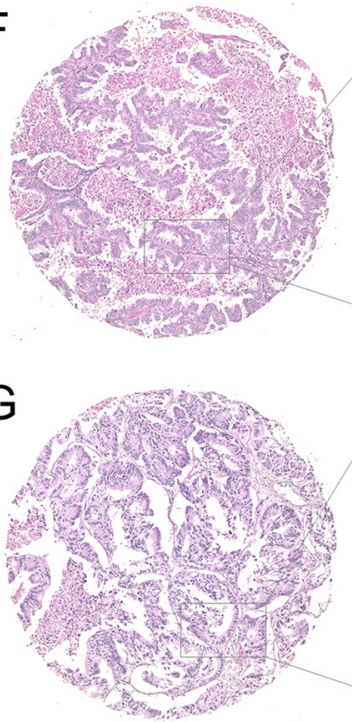

$\mathrm{H}$

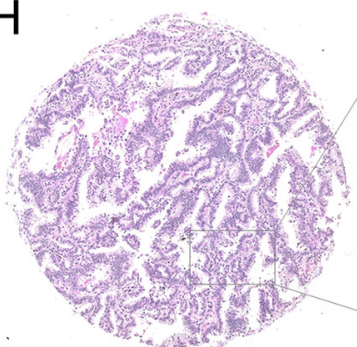

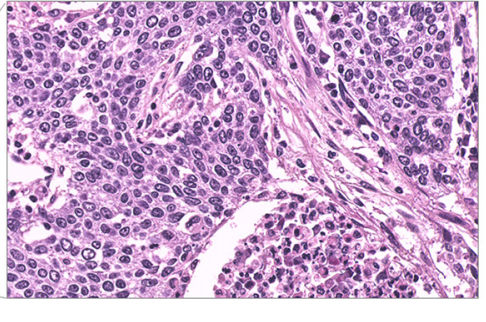
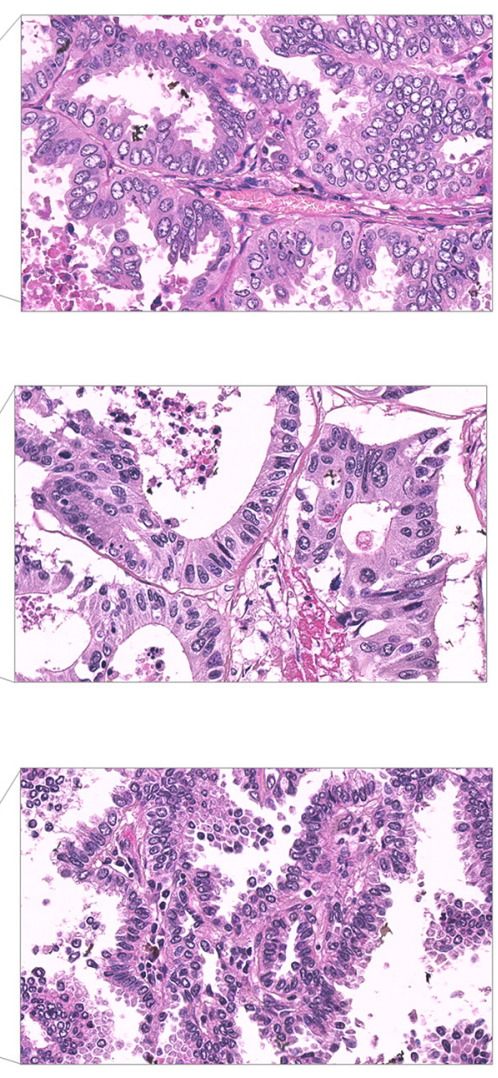

Fig 1. Morphological analysis of human lung specimens. Representative images of human lung sections stained with hematoxylin and eosin based on their pathology. (A) Healthy donor, (B) squamous cell carcinoma, (C) adenocarcinoma, (D) adenosquamous carcinoma, (E) small cell carcinoma, (F) papillary adenocarcinoma, $(\mathrm{G})$ metastatic adenocarcinoma, and $(\mathrm{H})$ bronchioloalveolar carcinoma. Scale bar $=250 \mu \mathrm{m}$. 
A

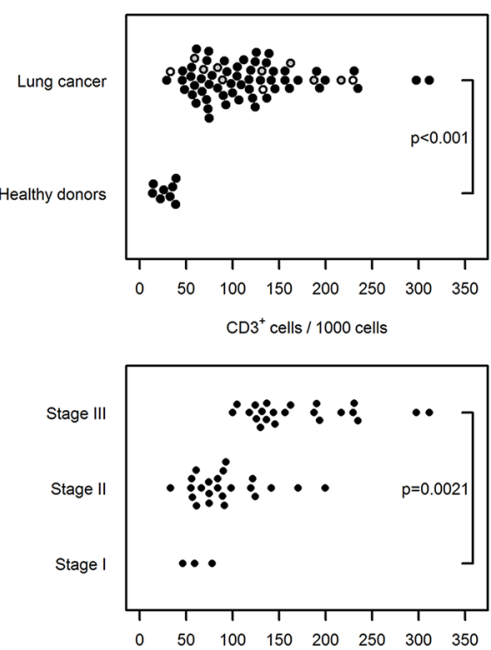

$\mathrm{CD}^{+}$cells $/ 1000$ cells

D

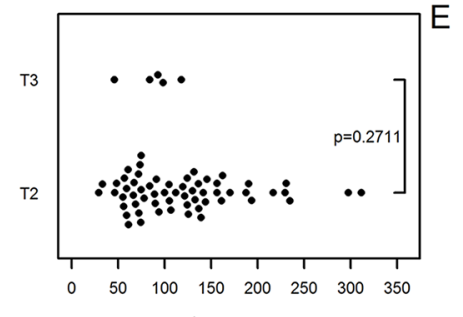

$\mathrm{CD}^{+}$cells $/ 1000$ cells

$\mathrm{F}$
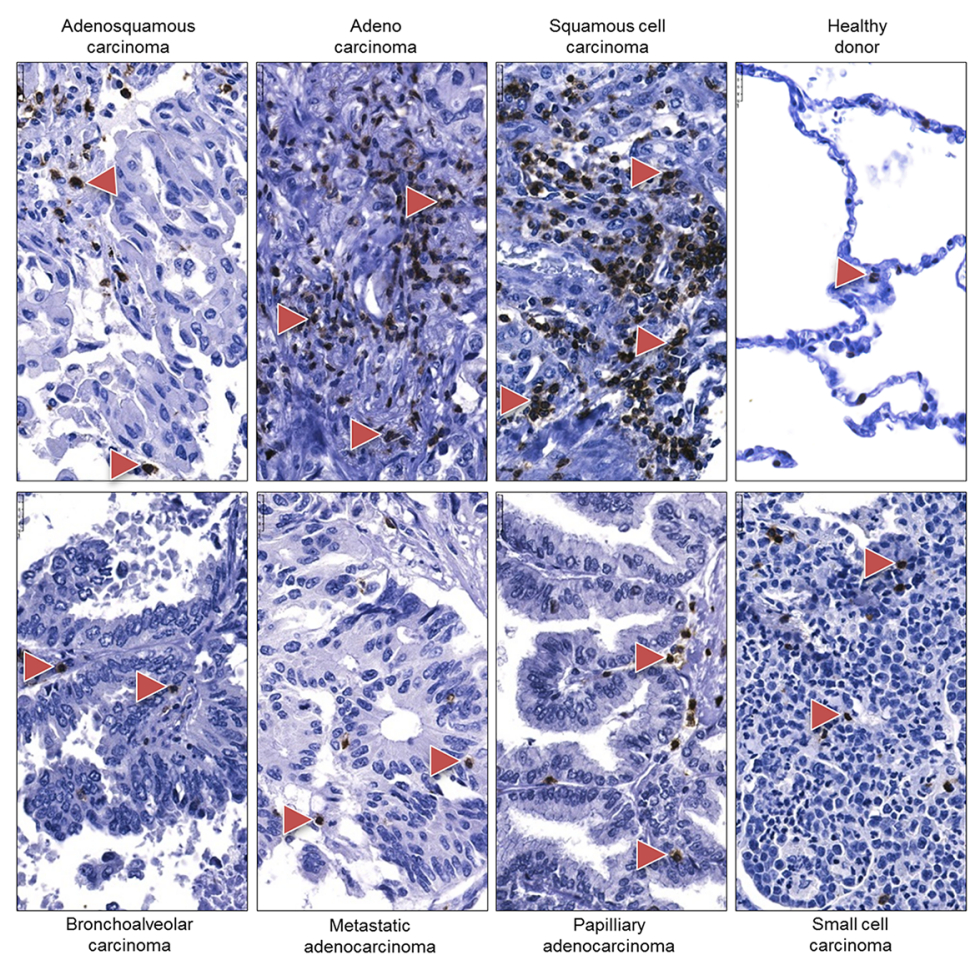

Fig 2. Immunohistochemical analysis and quantification of CD3-positive T lymphocytes in human lung cancer. Human lung cancer tissue array was stained with $C D 3$ antibody to detect $T$ lymphocytes. (A) Quantification of $\mathrm{CD}^{+}$cells in lung cancer vs. healthy donor specimens. (B-E) Quantification of $\mathrm{CD}^{+}$cells based on (B) their pathology, (C) cancer stage, (D) tumor size, and (E) nodal status. Cell numbers are given as CD3-positive cells per 1000 cells. (F) Representative images of human lung sections stained with CD3 antibody based on their pathology. Scale bar $=25 \mu \mathrm{m}$.

doi:10.1371/journal.pone.0139073.g002 
A

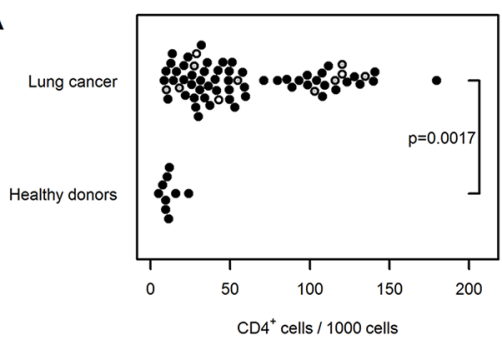

C

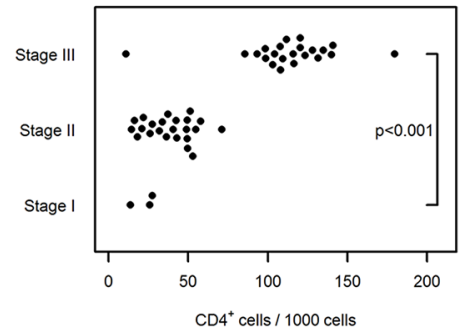

$\mathrm{D}$

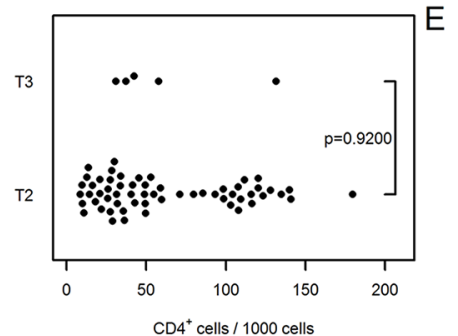

$\mathrm{F}$
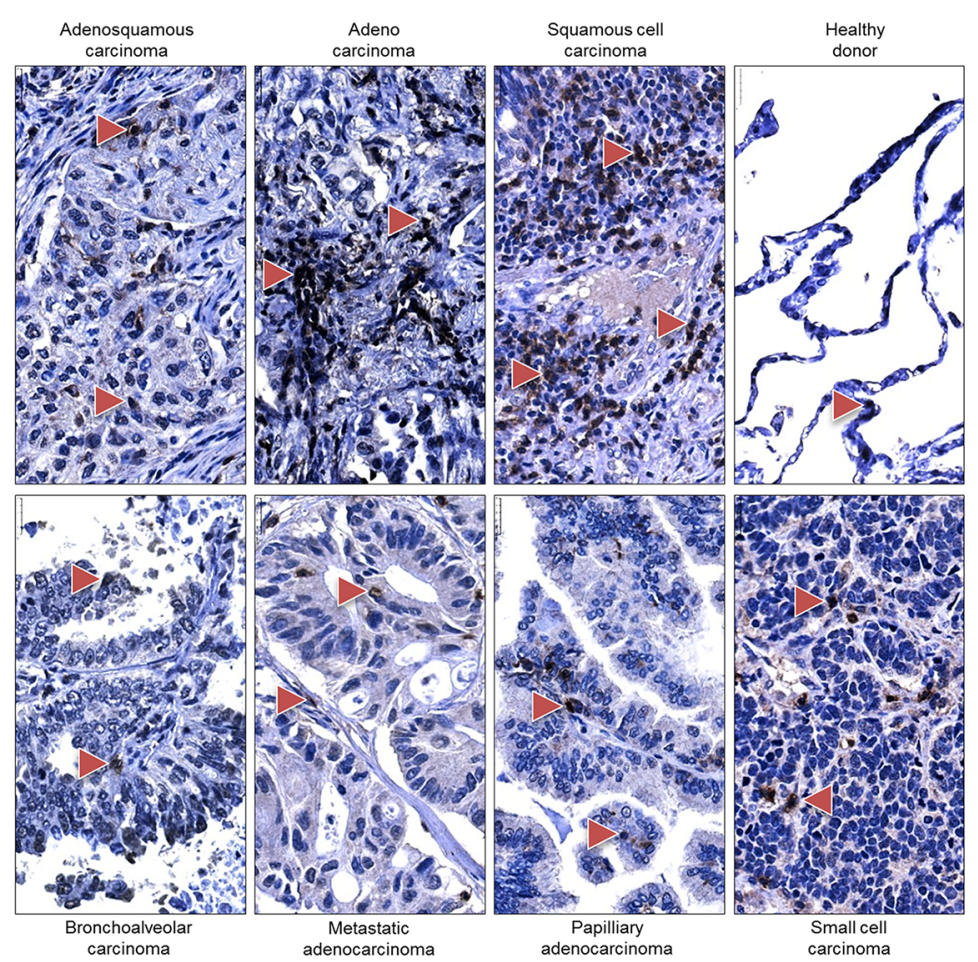

Fig 3. Immunohistochemical analysis and quantification of CD4-positive T lymphocytes in human lung cancer. Human lung cancer tissue array was stained with CD4 antibody to detect Thelper cells. (A) Quantification of $\mathrm{CD}^{+}$cells in lung cancer vs. healthy donor specimens. (B-E) Quantification of $\mathrm{CD} 4^{+}$cells based on (B) their pathology, (C) cancer stage, (D) tumor size, and (E) nodal status. Cell numbers are given as CD4-positive cells per 1000 cells. (F) Representative images of human lung sections stained with CD4 antibody based on their pathology. Scale bar $=25 \mu \mathrm{m}$.

doi:10.1371/journal.pone.0139073.g003 
A

Lung cancer

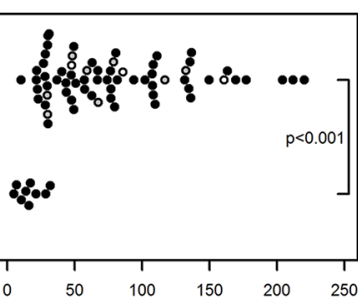

$\mathrm{CDB}^{+}$cells / 1000 cells

C

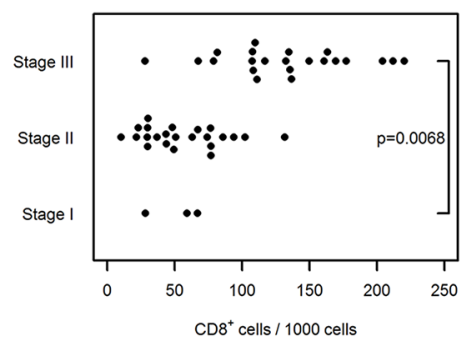

D

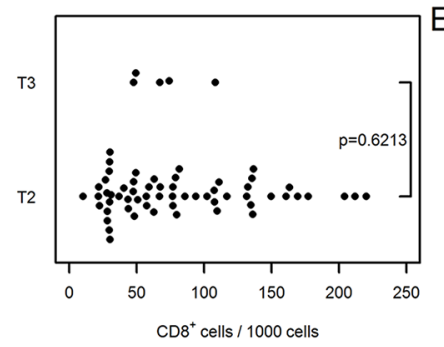

$\mathrm{F}$

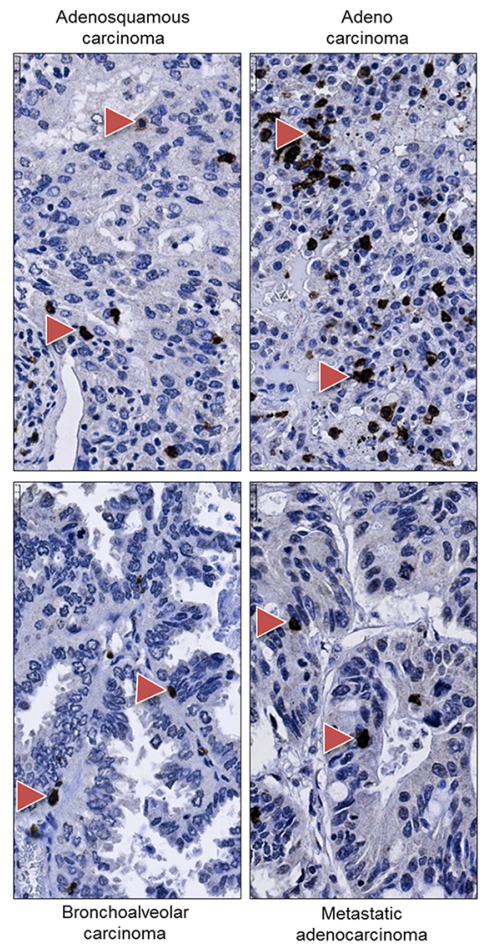

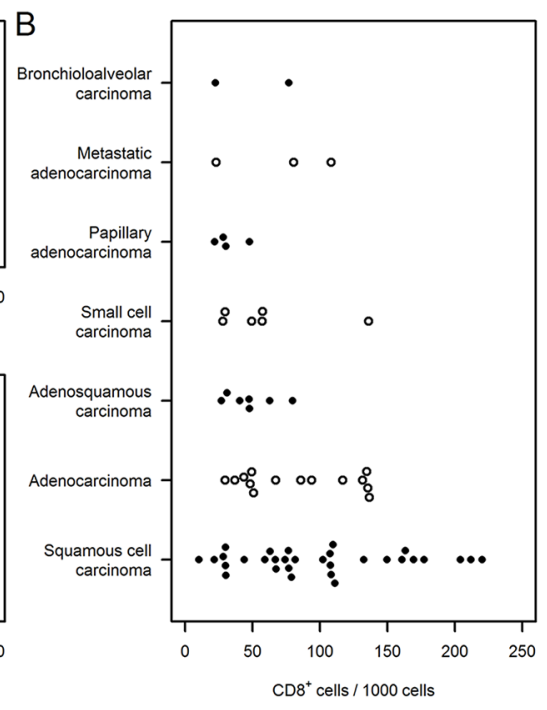

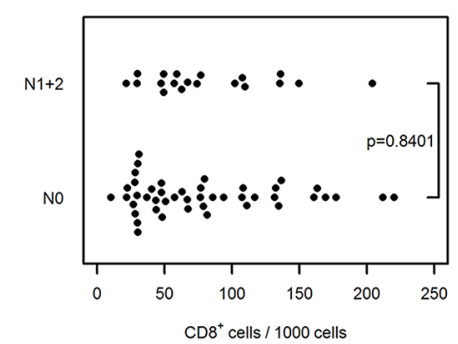

$F$
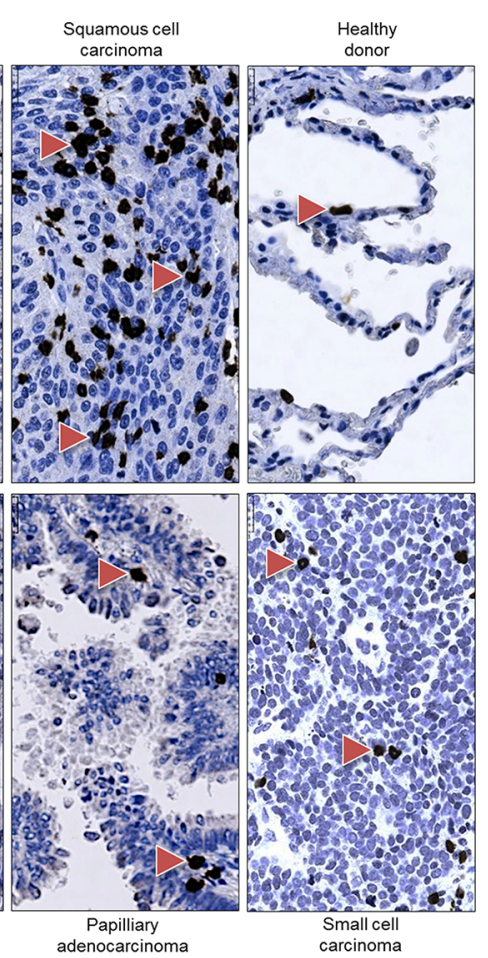

Fig 4. Immunohistochemical analysis and quantification of CD8-positive T lymphocytes in human lung cancer. Human lung cancer tissue array was stained with CD8 antibody to detect cytotoxic $T$ lymphocytes. (A) Quantification of $\mathrm{CD} 8^{+}$cells in lung cancer vs. healthy donor specimens. (B-E)

Quantification of $\mathrm{CD} 8^{+}$cells based on (B) their pathology, (C) cancer stage, (D) tumor size, and (E) nodal status. Cell numbers are given as CD8-positive cells per 1000 cells. (F) Representative images of human lung sections stained with CD8 antibody based on their pathology. Scale bar $=25 \mu \mathrm{m}$.

doi:10.1371/journal.pone.0139073.g004 
A Lung cancer

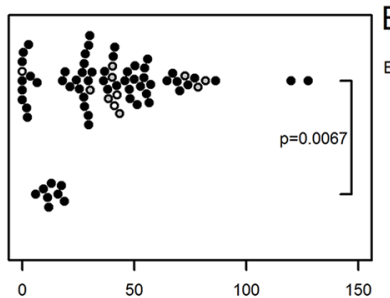

CD68 ${ }^{+}$cells / 1000 cells

C

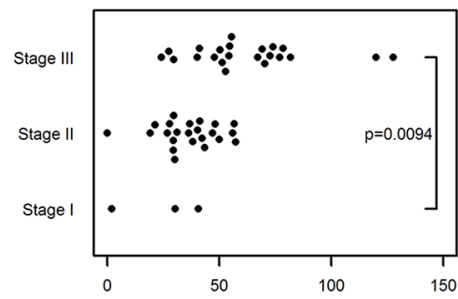

$\mathrm{CD}^{+} 8^{+}$cells $/ 1000$ cells

D

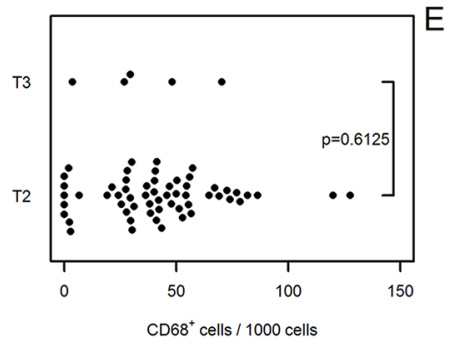

$\mathrm{F}$
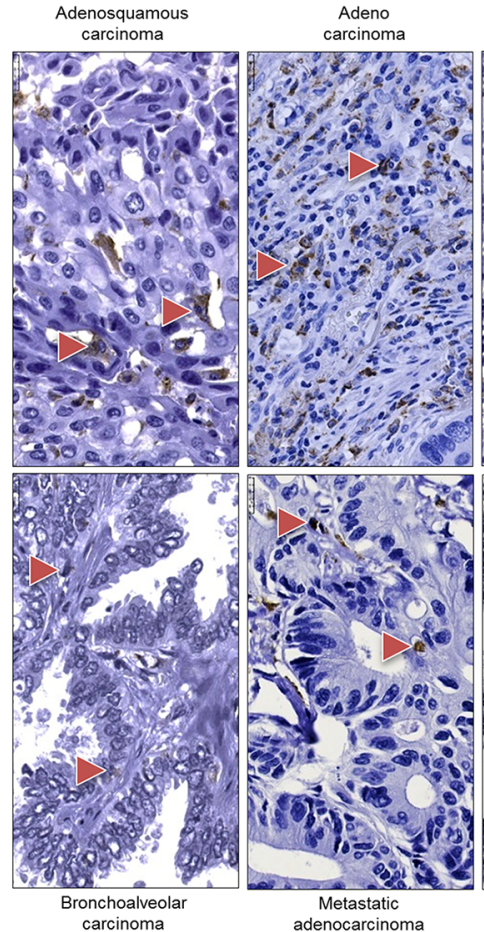

adenocarcinoma

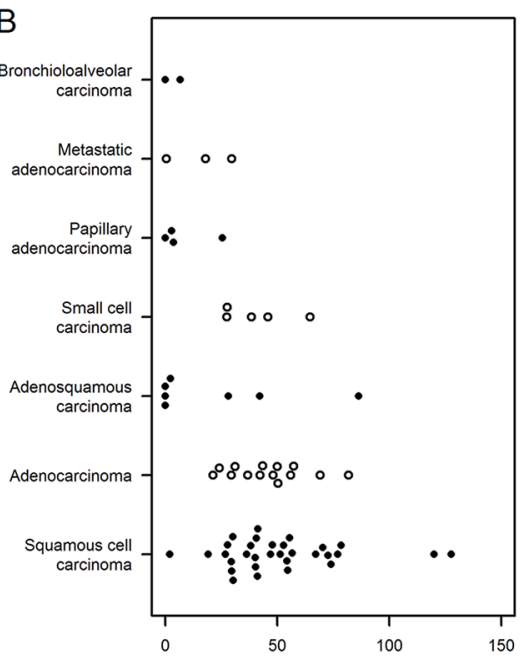

CD68 $8^{+}$cells / 1000 cells

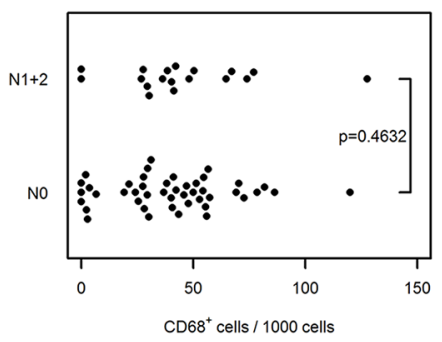

Squamous cell Healthy

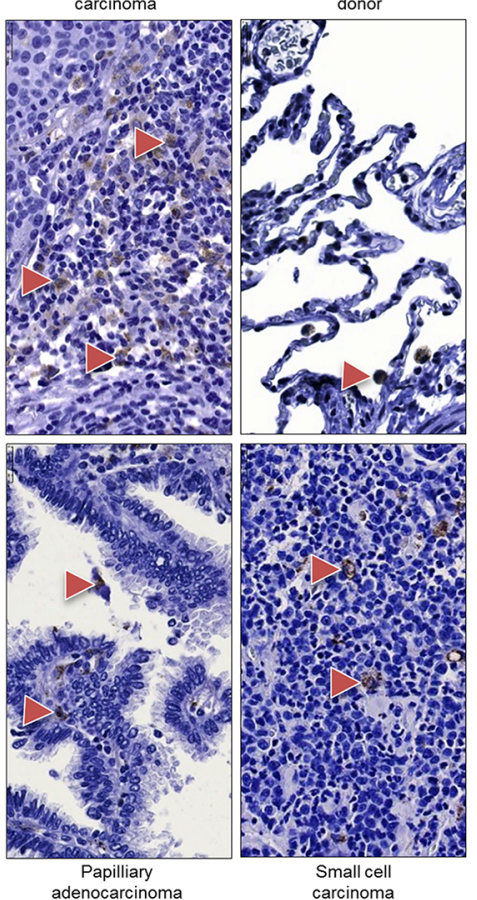

Fig 5. Immunohistochemical analysis and quantification of CD68-positive cells in human lung cancer. Human lung cancer tissue array was stained with CD68 antibody to detect macrophages. (A) Quantification of $\mathrm{CD}_{68}^{+}$cells in lung cancer vs. healthy donor specimens. (B-E) Quantification of $\mathrm{CD}^{+} 8^{+}$cells based on (B) their pathology, (C) cancer stage, (D) tumor size, and (E) nodal status. Cell numbers are given as CD68-positive cells per 1000 cells. (F) Representative images of human lung sections stained with CD68 antibody based on their pathology. Scale bar $=25 \mu \mathrm{m}$. 
A

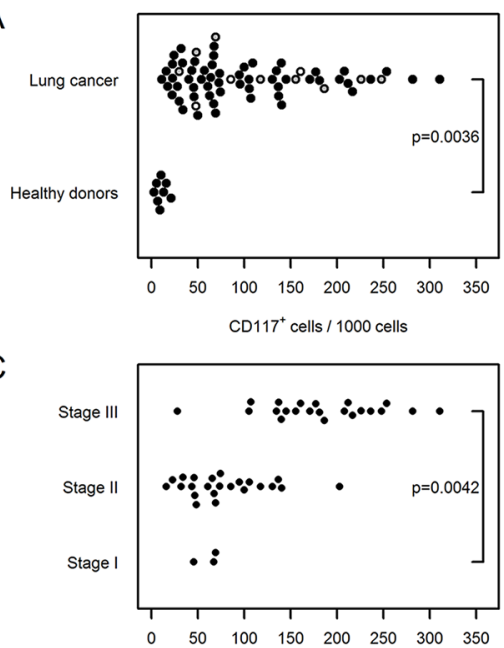

CD $117^{+}$cells $/ 1000$ cells

D

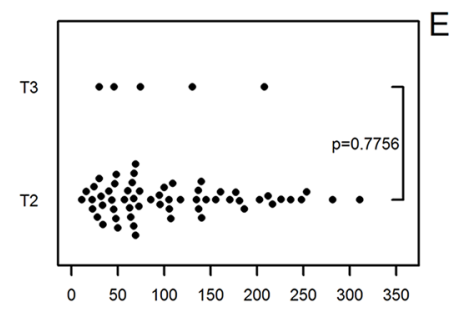

CD $117^{+}$cells $/ 1000$ cells

$\mathrm{F}$

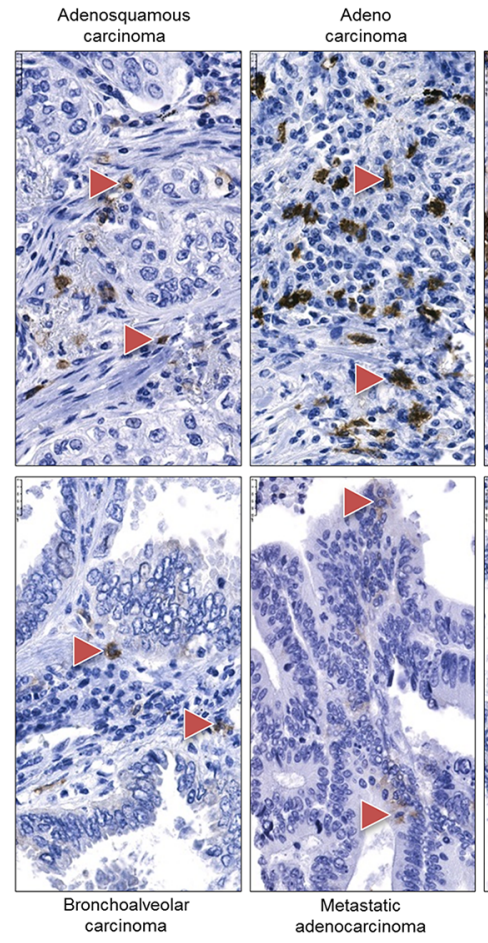

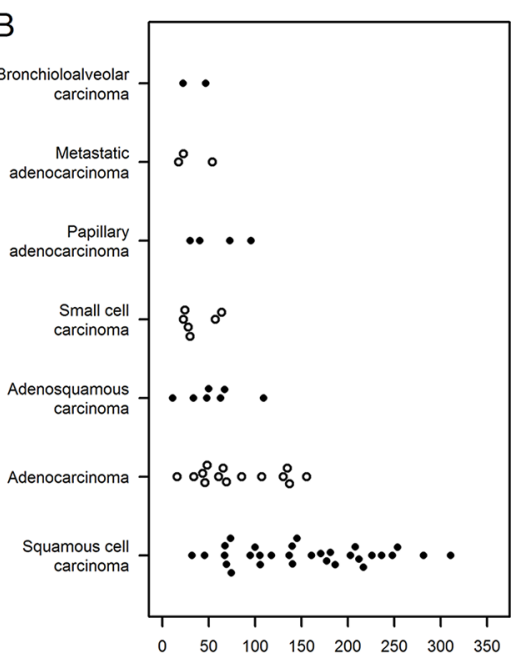

CD $117^{+}$cells $/ 1000$ cells

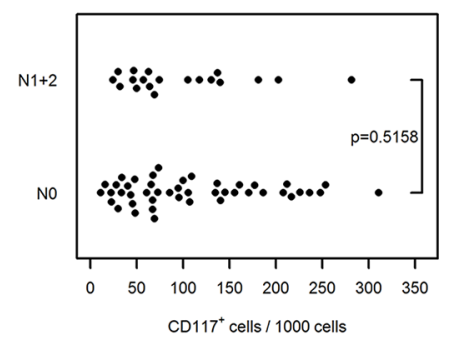

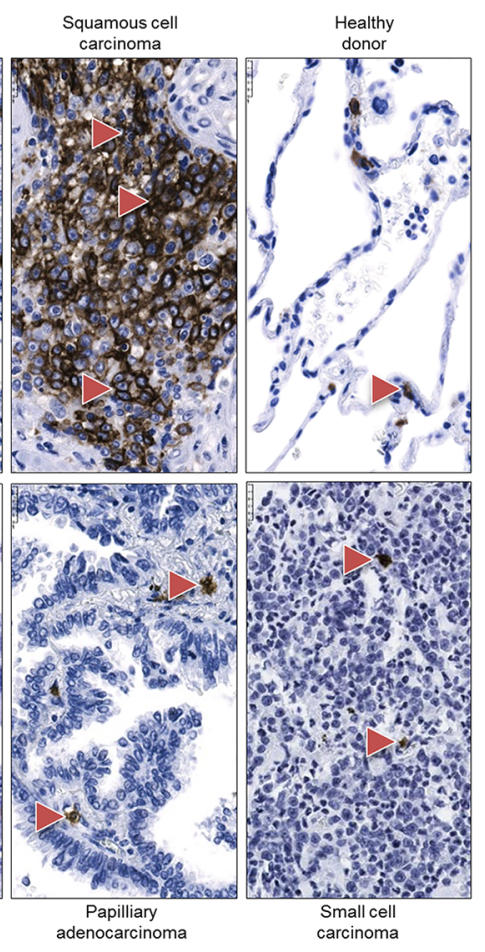

Fig 6. Immunohistochemical analysis and quantification of CD117-positive cells in human lung cancer. Human lung cancer tissue array was stained with CD117 (cKit) antibody to detect mast cells. (A) Quantification of $\mathrm{CD}_{117^{+}}$cells in lung cancer vs. healthy donor specimens. (B-E) Quantification of CD117 cells based on (B) their pathology, (C) cancer stage, (D) tumor size, and (E) nodal status. Cell numbers are given as CD117-positive cells per 1000 cells. (F) Representative images of human lung sections stained with CD117 antibody based on their pathology. Scale bar $=25 \mu \mathrm{m}$.

doi:10.1371/journal.pone.0139073.g006 
Granulocytes. The number of infiltrating neutrophil granulocytes was determined based on MPO immunoreactivity. Similar to the previous results, we found elevated numbers of neutrophils in the cancer tissue compared with healthy donor lungs $[74(62 \ldots 88)$ vs. $8(2 \ldots 34)$, Fig 7A] and in the later stages of cancer [stage III: 125 (107...145) vs. stage I: 37 (17 . .78), Fig 7C]. Similarly, there was no correlation between neutrophil number and cancer type, tumor size or nodal status (Fig 7B and 7D-7F).

B cells and dendritic cells. Next, based on the expression of CD20 and CD11c, we assessed the number of tumor-infiltrating $B$ cells and of dendritic cells (along with monocytes, macrophages, and neutrophils) respectively. We found an increase in $\mathrm{CD}_{2} 0^{+} \mathrm{B}$ cells within the tumor tissue compared with the healthy specimens $[39(30 \ldots 49)$ vs. $5(1 \ldots 34)$, Fig $8 \mathrm{~A}]$. The number of $\mathrm{CD} 20^{+}$cells was also elevated in stage III vs. stage I cancer samples [75 (62 . .92) vs. 9 (2. . 41), Fig 8C]. The numbers of of $\mathrm{CD} 20^{+} \mathrm{B}$ cells in cancer tissue was independent of cancer type and tumor size (Fig 8B, 8D and 8F). A considerably higher number of infiltrating $\mathrm{B}$ cells was detected in $\mathrm{N} 0$ tumor samples compared with $\mathrm{N} 1+2$ samples [45 (34 . .59) vs. 29 (18 . .49] (Fig $8 \mathrm{E}$ ). Likewise, the number of dendritic cells was substantially elevated within the tumor tis-

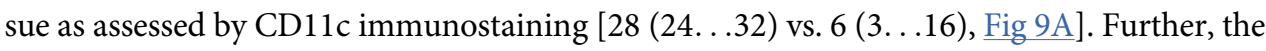
number of $\mathrm{CD} 11 \mathrm{c}^{+}$cells in the tumor tissue was independent of cancer type (Fig $9 \mathrm{~B}$ and $9 \mathrm{~F}$ ), although the number of infiltrating cells was elevated in later stages of lung cancer [47 (40. . .56) stage III vs. 11(4 . .28) stage I lung cancer, Fig 9C]. The number of CD11 $c^{+}$dendritic cells in tumor samples was independent of tumor size and nodal status (Fig 9D and 9E).

MUM1- and PD1-positive cells. We evaluated the expression levels of two additional immune markers. MUM1 labels plasma cells and activated T cells while PD1 labels activated T cells, B cells, myeloid cells and a subset of thymocytes. Both MUM1-positive cells and PD1positive cells were elevated in cancer tissue compared with control lungs [MUM1 ${ }^{+}$cells: 65 $(52 \ldots .81)$ vs. $6(1 \ldots 50), \mathrm{PD}^{+}$cells: $26(21 \ldots 32)$ vs. 9 (3 . .24), Figs $10 \mathrm{~A}$ and $\left.11 \mathrm{~A}\right]$. The prevalence of MUM1-positive cells was independent of the cancer type, stage, tumor size and nodal status (Fig 10B-10F). The number of PD1 ${ }^{+}$cells correlated with the cancer stage [stage III: 49 $(41 \ldots 58)$ vs. stage I: $5(1 \ldots 22)$, Fig $11 \mathrm{C}$ ], but there was no correlation with regard to cancer type, tumor size or nodal status (Fig 11B and 11D-11F).

\section{Discussion}

In this study, employing tissue arrays and immunohistochemistry, we comprehensively analyzed stromal cell composition in different human lung cancer types, grade and stage. In combination with an immunohistochemical analysis, we also employed a cyto-/histomorphological assessment of cells. This combination allowed us to classify/subclassify tumors accurately and to perform a high throughput analysis of stromal cell composition in tumor types with interindividual variability. Importantly, we observed extensive immune and inflammatory cell infiltration in human lung cancer samples. We comprehensively characterized and quantified $\mathrm{T}$ lymphocytes (CD3+), cytotoxic-T cells (CD8+), T-helper cells (CD4+), B cells (CD20+), macrophages $(\mathrm{CD} 68+)$, mast cells $(\mathrm{CD} 117+)$, mononuclear cells $(\mathrm{CD} 11 \mathrm{c}+)$, plasma cells and activated-T cells (MUM1+), activated-T cells, B cells, and myeloid cells (PD1+), and neutrophilic granulocytes (myeloperoxidase + ) in different lung cancer types, cancer stages, and nodal status.

In agreement with the studies of Ruffini et al. [16], we found an increase in the number of $\mathrm{CD}^{+}$lymphocytes in lung cancer tissue compared with healthy donor lungs. However, analysis of how T cells affect clinical outcome has often yielded contradictory results. Kilic et al. [18] reported that higher levels of tumor-infiltrating lymphocytes within large lung tumors correlate with a decreased risk of disease recurrence, whereas Kawai et al. reported no correlation 
A

C

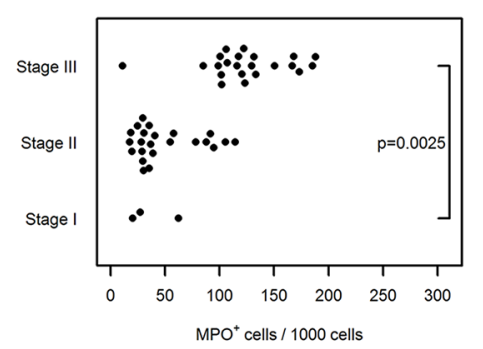

$\mathrm{D}$

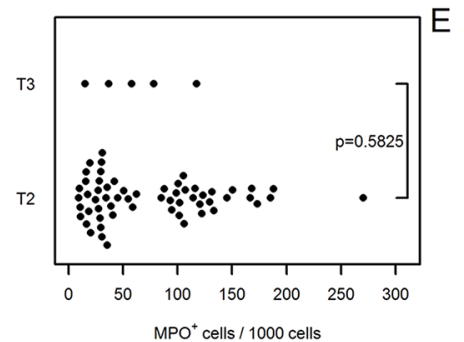

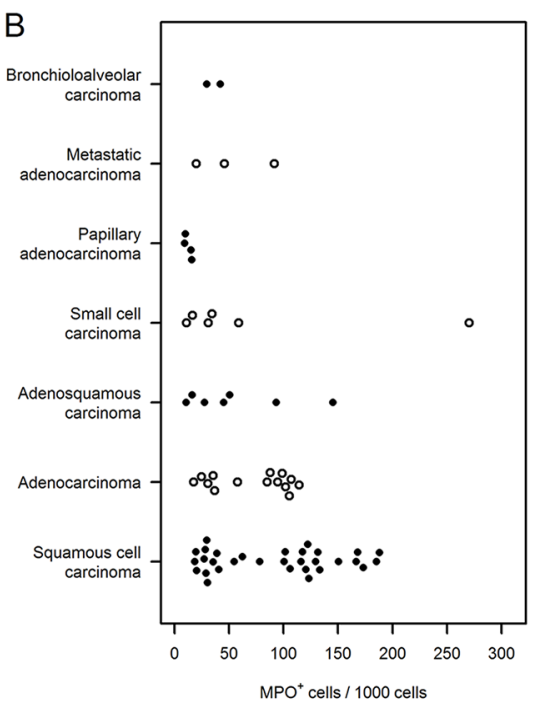

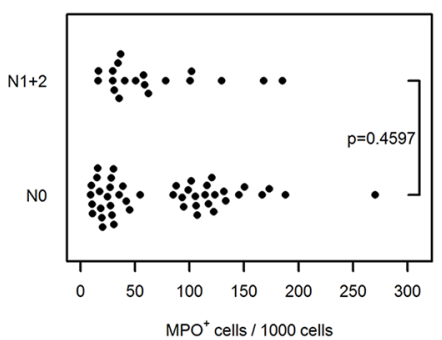

$\mathrm{MPO}^{+}$cells / 1000 cells

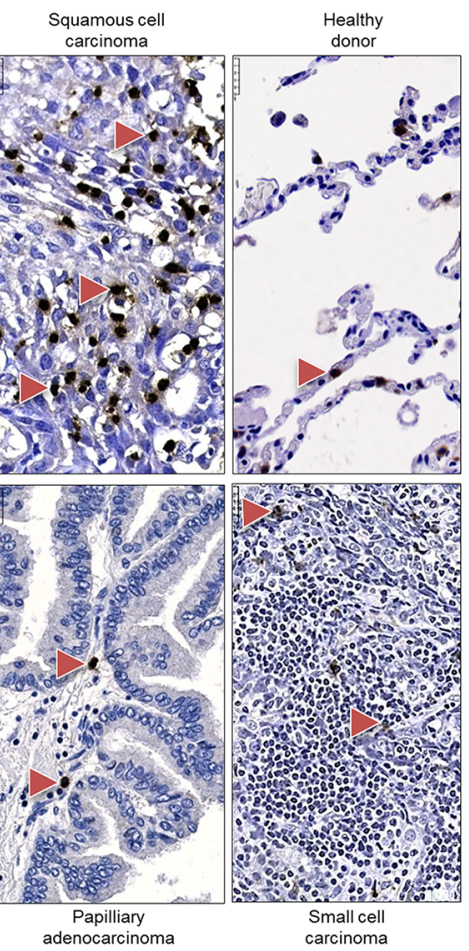

Fig 7. Immunohistochemical analysis and quantification of MPO-positive cells in human lung cancer. Human lung cancer tissue array was stained with MPO antibody to detect neutrophil granulocytes. (A) Quantification of $\mathrm{MPO}^{+}$cells in lung cancer vs. healthy donor specimens. (B-E) Quantification of $\mathrm{MPO}^{+}$cells based on (B) their pathology, (C) cancer stage, (D) tumor size, and (E) nodal status. Cell numbers are given as MPO-positive cells per 1000 cells. (F) Representative images of human lung sections stained with MPO antibody based on their pathology. Scale bar $=25 \mu \mathrm{m}$.

doi:10.1371/journal.pone.0139073.g007 
A

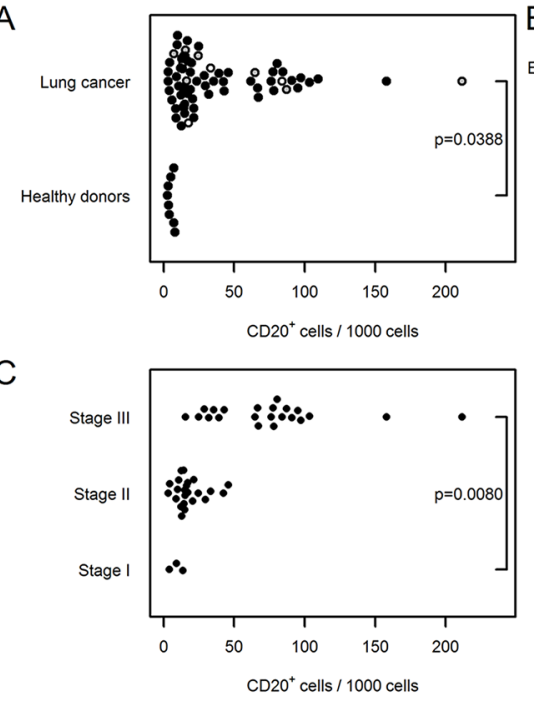

$\mathrm{D}$

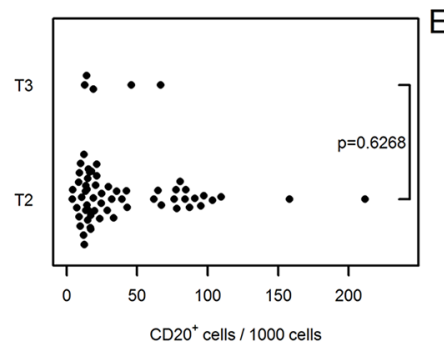

$\mathrm{F}$

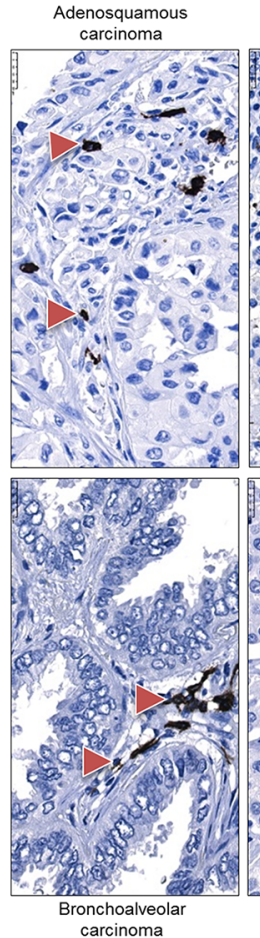

Adeno carcinoma
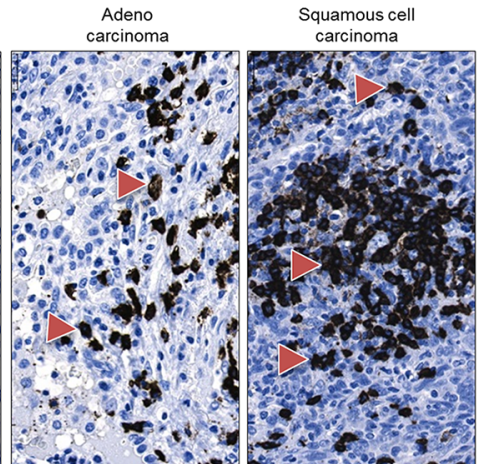

$20^{\circ}$ cells $/ 1000$ cells

Healthy
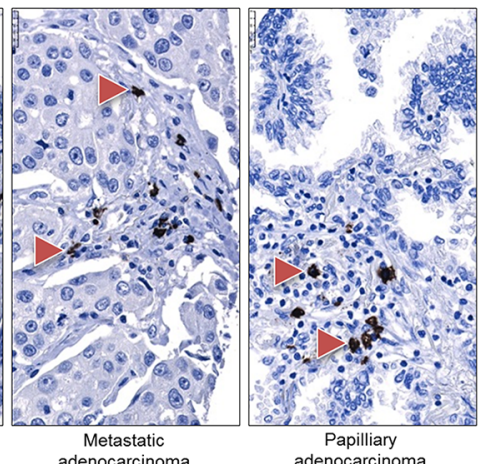
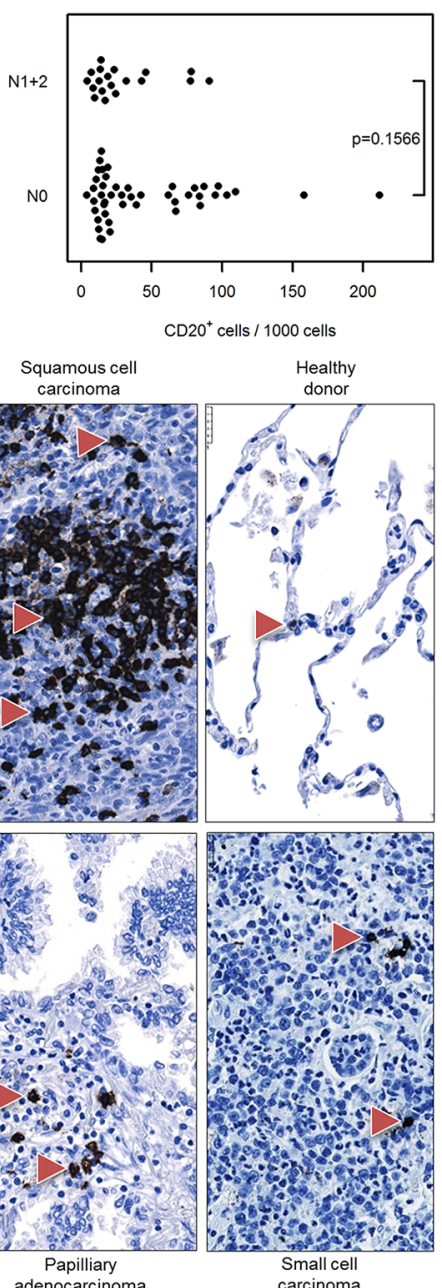

Fig 8. Immunohistochemical analysis and quantification of CD20-positive cells in human lung cancer. Human lung cancer tissue array was stained with CD20 antibody to detect B cells. (A) Quantification of $\mathrm{CD}^{2} \mathrm{O}^{+}$cells in lung cancer vs. healthy donor specimens. (B-E) Quantification of $\mathrm{CD} 20^{+}$cells based on (B) their pathology, (C) cancer stage, (D) tumor size, and (E) nodal status. Cell numbers are given as CD20-positive cells per 1000 cells. (F) Representative images of human lung sections stained with CD20 antibody based on their pathology. Scale bar $=25 \mu \mathrm{m}$. 
A

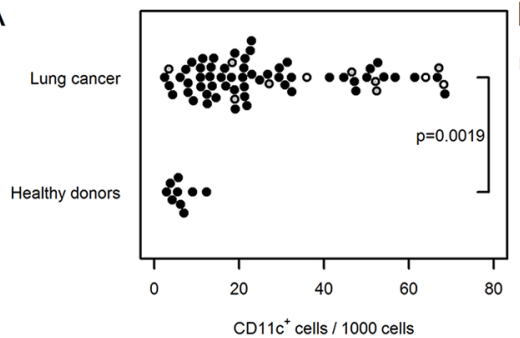

C

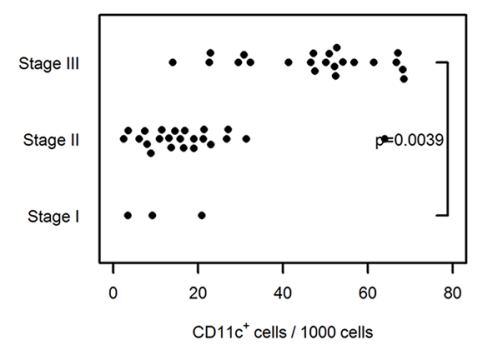

D

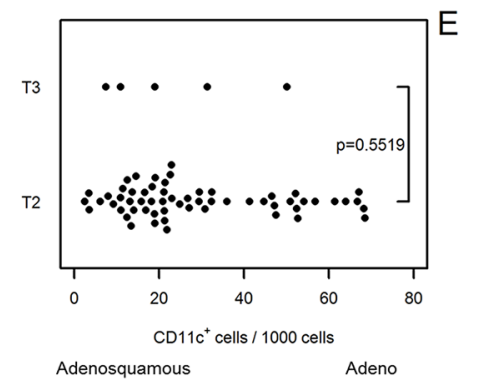

$\mathrm{F}$
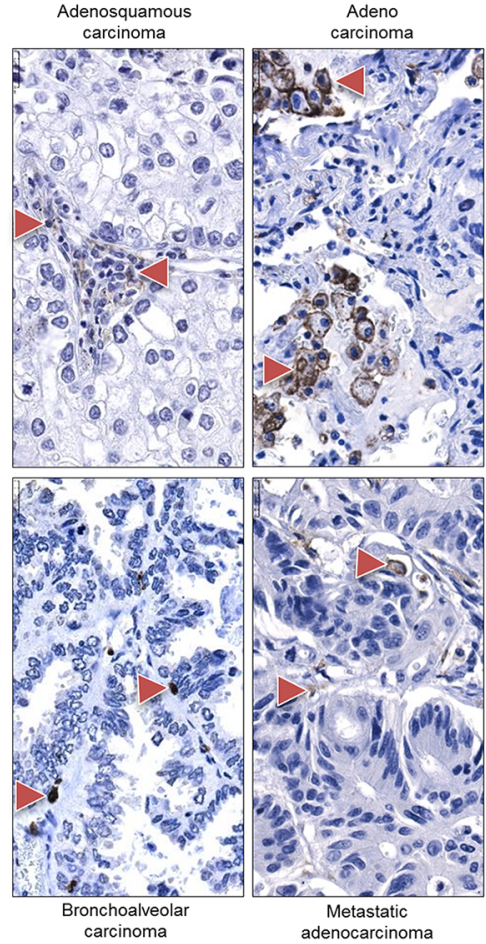

Fig 9. Immunohistochemical analysis and quantification of CD11c-positive cells in human lung cancer. Human lung cancer tissue array was stained with CD11c antibody to detect dendritic cells. (A) Quantification of $\mathrm{CD} 11 \mathrm{c}^{+}$cells in lung cancer vs. healthy donor specimens. (B-E) Quantification of CD11 $\mathrm{c}^{+}$ cells based on (B) their pathology, (C) cancer stage, (D) tumor size, and (E) nodal status. Cell numbers are given as CD11c-positive cells per 1000 cells. (F) Representative images of human lung sections stained with CD11c antibody based on their pathology. Scale bar $=25 \mu \mathrm{m}$.
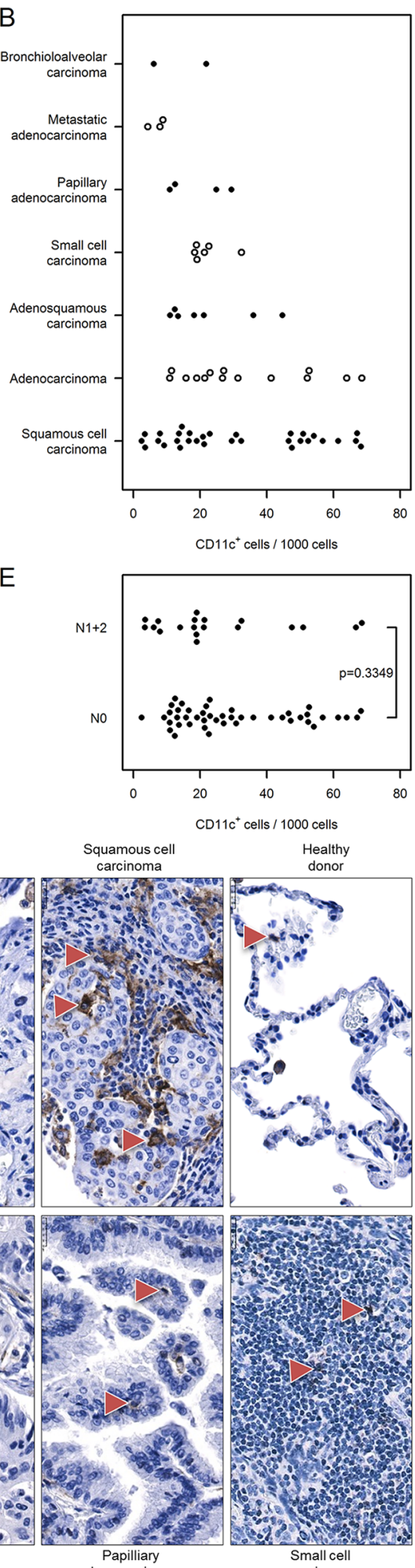

doi:10.1371/journal.pone.0139073.g009 
A

Lung cancer

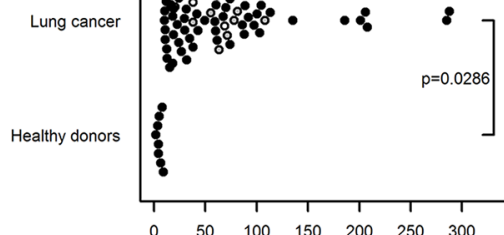

$\mathrm{MUM1}^{+}$cells / 1000 cells

C

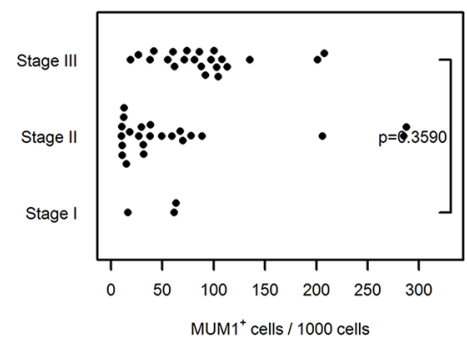

D

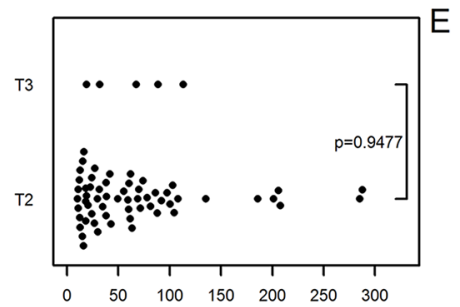

$\mathrm{MUM}^{+}{ }^{+}$cells / 1000 cells

$\mathrm{F}$
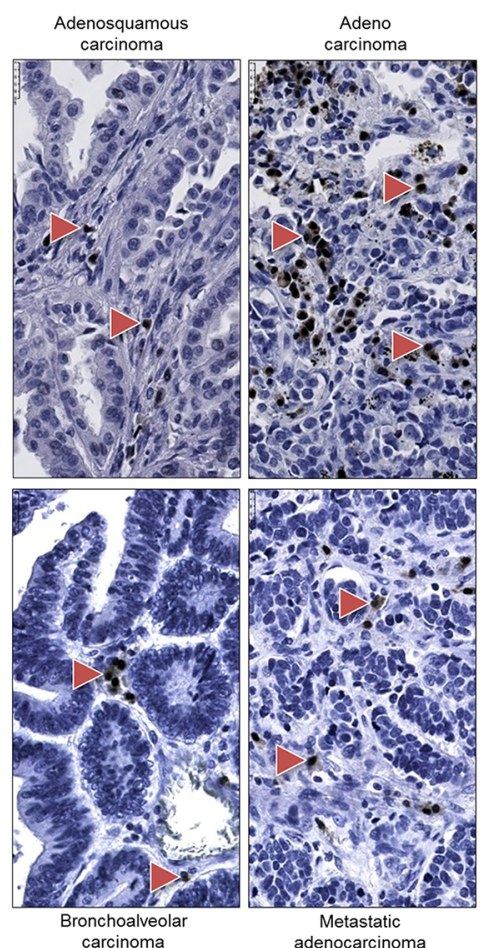

Fig 10. Immunohistochemical analysis and quantification of MUM1-positive cells in human lung cancer. Human lung cancer tissue array was stained with MUM1 antibody to detect plasma cells and activated T cells. (A) Quantification of $M U M 1^{+}$cells in lung cancer vs. healthy donor specimens. (B-E) Quantification of $\mathrm{MUM}^{+}{ }^{+}$cells based on (B) their pathology, (C) cancer stage, (D) tumor size, and (E) nodal status. Cell numbers are given as MUM1-positive cells per 1000 cells. (F) Representative images of human lung sections stained with MUM1 antibody based on their pathology. Scale bar $=25 \mu \mathrm{m}$.

doi:10.1371/journal.pone.0139073.g010 
A

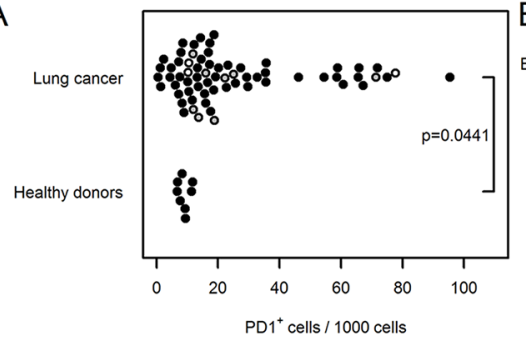

C

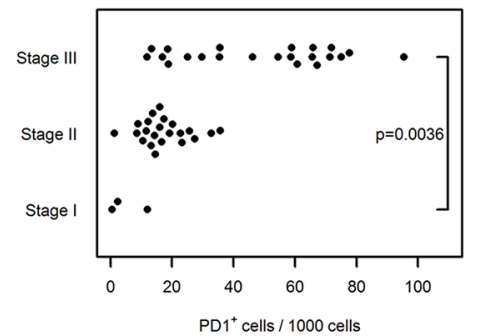

D

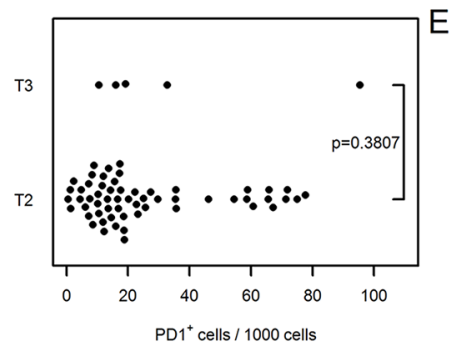

$\mathrm{F}$
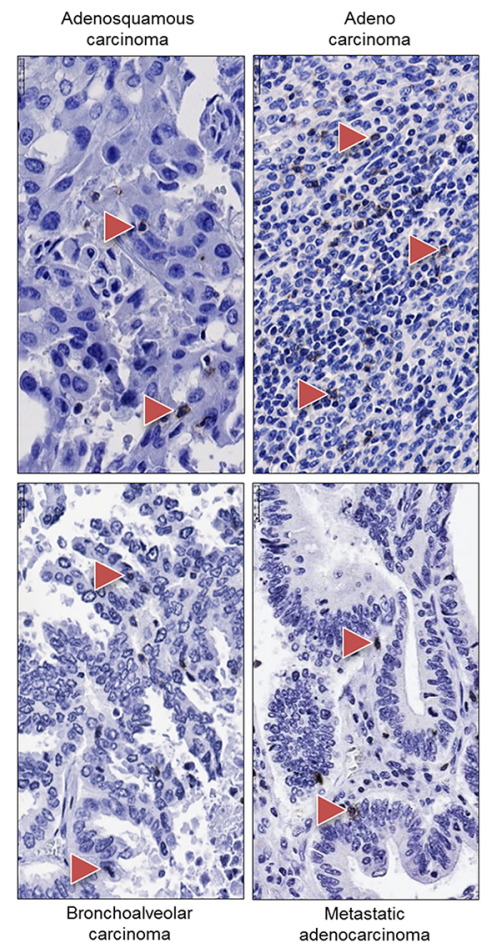

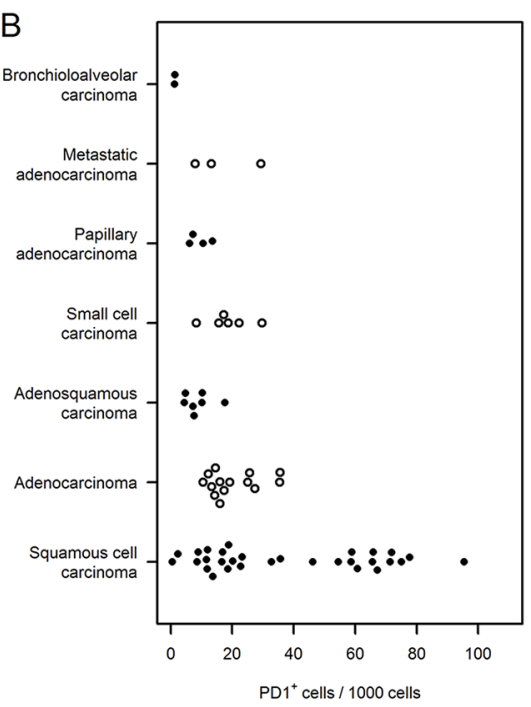

E

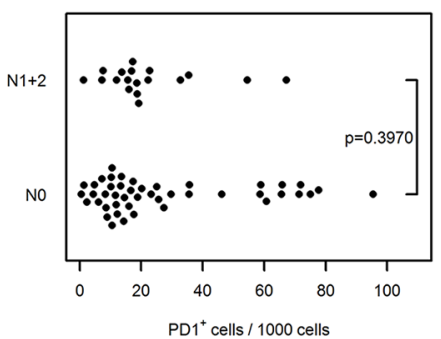

$\mathrm{PD} 1^{+}$cells / 1000 cells

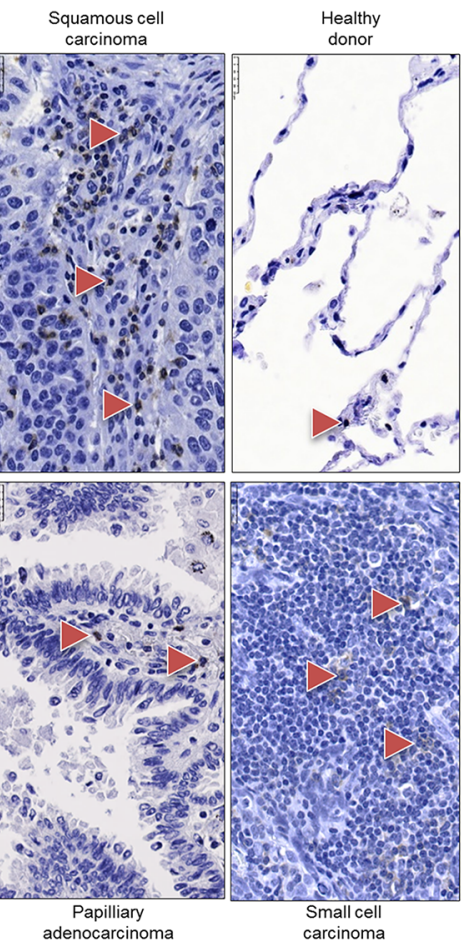

Fig 11. Immunohistochemical analysis and quantification of PD1-positive cells in human lung cancer. Human lung cancer tissue array was stained with PD1 antibody to detect activated T cells, B cells, myeloid cells, and a subset of thymocytes. (A) Quantification of PD1 ${ }^{+}$cells in lung cancer vs. healthy donor specimens. (B-E) Quantification of PD1 ${ }^{+}$cells based on (B) their pathology, (C) cancer stage, (D) tumor size, and (E) nodal status. Cell numbers are given as PD1-positive cells per 1000 cells. (F) Representative images of human lung sections stained with PD1 antibody based on their pathology. Scale bar $=25 \mu \mathrm{m}$. 
between the number of tumor-infiltrating lymphocytes and patient survival [17]. In our study, in addition to general analysis of tumor-infiltrating lymphocytes, analysis of specific T-cell subsets demonstrated a significant increase in tumor-infiltrating Thelper cells $\left(\mathrm{CD} 4^{+}\right)$as well as cytotoxic $\mathrm{T}$ cells $\left(\mathrm{CD}^{+}\right)$compared with healthy donor lungs. Tumor-infiltrating lymphocytes are thought to play an important role in anticancer immunosurveillance [17]. $\mathrm{CD} 8^{+} \mathrm{T}$ cells recognize and destroy cancer cells while $\mathrm{CD} 4^{+}$cells aid $\mathrm{CD}^{+}{ }^{+} \mathrm{T}$ cells in tumor rejection. Therefore, their number and localization in tumor tissue may influence tumorigenicity [26]. Although high in number, $\mathrm{CD} 8^{+} \mathrm{T}$ cells that infiltrate lung tumors may be dysfunctional due to tumor microenvironmental factors which may subsequently lead to reduced numbers of effector $\mathrm{CD} 8^{+} \mathrm{T}$ cells [27]. These altered $\mathrm{CD} 8^{+} \mathrm{T}$ cells may even release compounds that promote tumor progression. Thus, a deeper understanding and dissection of the contribution of different $\mathrm{CD}^{+}$and $\mathrm{CD}^{+}{ }^{+} \mathrm{T}$ cell subpopulations (e.g., Th1, Th2, Th17, Tc9, Tc17) is necessary.

Among phagocytes and granulocytes, we observed that higher numbers of infiltrating macrophages, mast cells, and neutrophils correlated positively with tumor stage in human lung cancer patients. The density of macrophages within tumor islets and the ratio of macrophages situated in these islets to the stromal macrophages are positive prognostic factors for patient survival $[17,28]$. In contrast, other studies have suggested that both M1 and M2 macrophages favor carcinogenesis [29] and their numbers within the cancer may be negative prognostic factors [30]. We observed that macrophage infiltration correlated positively with tumor stage and nodal status/ metastasis in human lung cancer patients suggesting an important contribution of these tumor-associated macrophages in lung cancer progression and metastasis. To confirm the importance of macrophages, future studies should address the subtypes of macrophages present in the microenvironment of the lung tumor since recent studies suggest that during carcinogenesis, macrophages may polarize to M1 (anti-tumorigenic) and M2 (contributing to carcinogenesis) subtypes and thus can exert differential effects [31]. Furthermore, we need to understand how the bidirectional cross talk between macrophages and cancer cells influences these cells as well as dissecting the underlying molecular mechanisms [32]. We recently provided evidence that macrophage and cancer cell cross talk via CCR2 and CX3CR1, a fundamental mechanism driving lung cancer [12]. These findings suggest that the therapeutic strategy of blocking CCR2 and CX3CR1 may prove beneficial for halting lung cancer progression.

Regarding mast cells, Welsh and colleagues [28] showed that an increased islet/stromal mast cell ratio is an advantageous independent prognostic factor, whereas Kawai et al. [17] found no correlation with clinical outcome. Here, we showed that the mast cell number was higher in tumor tissue compared with healthy donors and was substantially elevated in stage III cancer compared with stage I.

Neutrophil granulocytes have received increased attention as a new type of tumor-infiltrating immune cell that plays a role in tumor growth. However, little is known about their role in lung cancer. It has been suggested that increased numbers of neutrophils have been observed in the bronchoalveolar lavage fluid of patients with bronchioloalveolar carcinoma, and serves as an independent predictor of clinical outcome [33]. Here we show an elevated number of neutrophils in lung cancer specimens compared with healthy lung and a strong association with advanced lung cancer stages.

Dendritic cells are a potent, heterogeneous group of antigen-presenting cells that are important for primary immune responses to carcinoma. We found a significant increase in CD11cpositive cells within the tumor mass in advanced-stage cancer samples compared with healthy donors. We speculate that the vast majority of these cells correspond to dendritic cells, but we cannot exclude the possibility that a portion may be monocytes, macrophages, or neutrophils, which also express CD11c [34]. Although we did not assess the maturity of dendritic cells, 
previous work [35] hinted that at least some of the tumor-infiltrating dendritic cells display an immature phenotype in non-small-cell lung cancer and that this may be due to several tumorderived factors.

Among the other antigen-presenting cells, we found an increased number of CD20-positive $B$ cells in lung cancer samples compared with healthy donor tissue. As the role of B cells in cancer progression is rather debatable $[16,19,36]$, we additionally assessed the number of MUM1-positive plasma cells in tumor and healthy human lung tissue. Plasma cells originate from $B$ cells upon their encounter with a foreign antigen and are the sole producers of antibodies [37]. We found increased numbers of plasma cells in cancer tissue compared with donor lungs, a result that was independent of the cancer stage as well as other measured parameters. The role of plasma cells in solid tumors has not been intensively investigated, and thus only a few reports of their role in lung cancer exist. Lohr and colleagues showed that infiltration of mature plasma cells into tumor tissue is associated with prolonged survival [38]. Another study reported infiltration of IgG4-positive plasma cells in specimens of stage I squamous cell carcinoma that were associated with favorable prognosis [39].

$\mathrm{PD} 1$ is an immunoglobulin superfamily member found primarily on immature $\mathrm{CD} 4^{-} \mathrm{CD} 8^{-}$ thymocytes during $\mathrm{T}$-cell receptor- $\beta$ rearrangement. Upon activation, PD1 may also be expressed on peripheral T helper and cytotoxic $\mathrm{T}$ cells, B lymphocytes, natural killer $\mathrm{T}$ cells, and monocytes [40]. PD1 function is best characterized in T cells, where it plays a vital role in the induction and maintenance of anergy and peripheral tolerance of $T$ cells by inhibiting their proliferation and cytokine production [40,41]. Here, we show a significantly increased number of PD1-positive cells in lung cancer tissue compared with healthy control lungs. The number of $\mathrm{PD}^{+}$cells correlated with cancer stage but was independent of cancer type, tumor size and nodal status. Our finding that the number of $\mathrm{PD}^{+}$cells correlated with the cancer stage is of interest, as recent studies suggest that PD1 signaling status (e.g. PD-ligand 1 expression) may be a potential predictive biomarker for anti-PD-1 therapy [42]. In conclusion, the immune infiltrates are of major importance in development and progression of lung cancer and in determining prognosis of patients with lung cancer.

\section{Strengths and limitations of the study}

In this study, employing tissue arrays and immunohistochemistry, we comprehensively analyzed stromal cell composition in different human lung cancer types, grade and stage. As demonstrated in our study we were successful in high throughput analysis of stromal cell composition in tumor types with inter-individual variability using tissue arrays. Therefore, application of a tissue array with lung carcinoma cores is suitable and feasible. However, with this technology, our ability to characterize in detail the tumor heterogeneity is limited. As we have only duplicate cores per sample in the tissue arrays used, the issue of tumor heterogeneity cannot be addressed in detail. Moreover, it must be taken into account that in a few instances, cores do not contain tumor, thus a careful morphological checkup is necessary. In addition, we can detect unspecific staining by suboptimal immunohistochemical labeling, which can be circumvented by correlation to cell morphology and background. Thus we believe this technology requires well-experienced personnel. One other alternative method that could be developed is multiparameter assessment of immune and inflammatory cell composition of human lung cancer stroma using flow cytometry or confocal microscopy, which is beyond the scope of the present study.

\section{Acknowledgments}

The authors thank Yanina Knepper, Vanessa Golchert for immunohistochemical analysis and Dr. Matthew Wheeler for careful proofreading of the manuscript. 


\section{Author Contributions}

Conceived and designed the experiments: GB SP JW AW RS. Performed the experiments: GB AT CO KE. Analyzed the data: GB SP JW TS FG WS LF RS. Contributed reagents/materials/ analysis tools: GB TS FG WS LF RS. Wrote the paper: GB AT SP JW AW KE TS FG WS LF RS.

\section{References}

1. Siegel R, Naishadham D, Jemal A. Cancer statistics, 2013. CA Cancer J Clin. 2013; 63(1):11-30. doi: 10.3322/caac.21166 PMID: 23335087.

2. Jemal $A$, Bray F, Center MM, Ferlay J, Ward E, Forman D. Global cancer statistics. CA: a cancer journal for clinicians. 2011; 61(2):69-90. Epub 2011/02/08. doi: 10.3322/caac.20107 PMID: 21296855.

3. Nana-Sinkam SP, Powell CA. Molecular biology of lung cancer: Diagnosis and management of lung cancer, 3rd ed: American College of Chest Physicians evidence-based clinical practice guidelines. Chest. 2013; 143(5 Suppl):e30S-9S. Epub 2013/05/10. doi: 10.1378/chest.12-2346 PMID: 23649444; PubMed Central PMCID: PMC3961820.

4. Lorenz J, Friedberg T, Paulus R, Oesch F, Ferlinz R. Oncogene overexpression in non-small-cell lung cancer tissue: prevalence and clinicopathological significance. Clin Investig. 1994; 72(2):156-63. PMID: 8186664.

5. Peifer M, Fernandez-Cuesta L, Sos ML, George J, Seidel D, Kasper LH, et al. Integrative genome analyses identify key somatic driver mutations of small-cell lung cancer. Nat Genet. 2012; 44(10):1104-10. doi: 10.1038/ng.2396 PMID: 22941188.

6. Hanahan D, Weinberg RA. Hallmarks of cancer: the next generation. Cell. 2011; 144(5):646-74. Epub 2011/03/08. doi: 10.1016/j.cell.2011.02.013 PMID: 21376230.

7. Swartz MA, lida N, Roberts EW, Sangaletti S, Wong MH, Yull FE, et al. Tumor microenvironment complexity: emerging roles in cancer therapy. Cancer Res. 2012; 72(10):2473-80. Epub 2012/03/15. doi: 10.1158/0008-5472.CAN-12-0122 PMID: 22414581; PubMed Central PMCID: PMC3653596.

8. Hanahan D, Coussens LM. Accessories to the crime: functions of cells recruited to the tumor microenvironment. Cancer cell. 2012; 21(3):309-22. Epub 2012/03/24. doi: 10.1016/j.ccr.2012.02.022 PMID: 22439926.

9. Remark R, Becker C, Gomez JE, Damotte D, Dieu-Nosjean MC, Sautes-Fridman C, et al. The nonsmall cell lung cancer immune contexture. A major determinant of tumor characteristics and patient outcome. Am J Respir Crit Care Med. 2015; 191(4):377-90. Epub 2014/11/05. doi: 10.1164/rccm.2014091671PP PMID: 25369536.

10. Bindea G, Mlecnik B, Tosolini M, Kirilovsky A, Waldner M, Obenauf AC, et al. Spatiotemporal dynamics of intratumoral immune cells reveal the immune landscape in human cancer. Immunity. 2013; 39 (4):782-95. Epub 2013/10/22. doi: 10.1016/j.immuni.2013.10.003 PMID: 24138885.

11. Murdoch $\mathrm{C}$, Muthana $\mathrm{M}, \mathrm{Coffelt} \mathrm{SB}$, Lewis $\mathrm{CE}$. The role of myeloid cells in the promotion of tumour angiogenesis. Nature reviews Cancer. 2008; 8(8):618-31. Epub 2008/07/18. doi: 10.1038/nrc2444 PMID: 18633355.

12. Schmall A, Al-Tamari HM, Herold $S$, Kampschulte $M$, Weigert $A$, Wietelmann $A$, et al. Macrophage and cancer cell cross-talk via CCR2 and CX3CR1 is a fundamental mechanism driving lung cancer. Am J Respir Crit Care Med. 2015; 191(4):437-47. Epub 2014/12/24. doi: 10.1164/rccm.201406-1137OC PMID: 25536148.

13. El-Nikhely N, Larzabal L, Seeger W, Calvo A, Savai R. Tumor-stromal interactions in lung cancer: novel candidate targets for therapeutic intervention. Expert Opin Investig Drugs. 2012; 21(8):1107-22. doi: 10.1517/13543784.2012.693478 PMID: 22667993.

14. Tartour E, Zitvogel L. Lung cancer: potential targets for immunotherapy. The Lancet Respiratory medicine. 2013; 1(7):551-63. Epub 2014/01/28. doi: 10.1016/S2213-2600(13)70159-0 PMID: 24461616.

15. Kataki $A$, Scheid $P$, Piet $M$, Marie $B$, Martinet $N$, Martinet $Y$, et al. Tumor infiltrating lymphocytes and macrophages have a potential dual role in lung cancer by supporting both host-defense and tumor progression. J Lab Clin Med. 2002; 140(5):320-8. doi: 10.1067/mlc.2002.128317 PMID: 12434133.

16. Ruffini E, Asioli S, Filosso PL, Lyberis $P$, Bruna MC, Macri L, et al. Clinical significance of tumor-infiltrating lymphocytes in lung neoplasms. Ann Thorac Surg. 2009; 87(2):365-71; discussion 71-2. doi: 10. 1016/j.athoracsur.2008.10.067 PMID: 19161739.

17. Kawai O, Ishii G, Kubota K, Murata Y, Naito Y, Mizuno T, et al. Predominant infiltration of macrophages and CD8(+) T Cells in cancer nests is a significant predictor of survival in stage IV nonsmall cell lung cancer. Cancer. 2008; 113(6):1387-95. doi: 10.1002/cncr.23712 PMID: 18671239. 
18. Kilic A, Landreneau RJ, Luketich JD, Pennathur A, Schuchert MJ. Density of tumor-infiltrating lymphocytes correlates with disease recurrence and survival in patients with large non-small-cell lung cancer tumors. J Surg Res. 2011; 167(2):207-10. doi: 10.1016/j.jss.2009.08.029 PMID: 19896677.

19. Al-Shibli KI, Donnem T, Al-Saad S, Persson M, Bremnes RM, Busund LT. Prognostic effect of epithelial and stromal lymphocyte infiltration in non-small cell lung cancer. Clin Cancer Res. 2008; 14(16):52207. doi: 10.1158/1078-0432.CCR-08-0133 PMID: 18698040.

20. Savai R, Pullamsetti SS, Kolbe J, Bieniek E, Voswinckel R, Fink L, et al. Immune and inflammatory cell involvement in the pathology of idiopathic pulmonary arterial hypertension. Am J Respir Crit Care Med. 2012; 186(9):897-908. doi: 10.1164/rccm.201202-0335OC PMID: 22955318.

21. Savai R, Al-Tamari HM, Sedding D, Kojonazarov B, Muecke C, Teske R, et al. Pro-proliferative and inflammatory signaling converge on FoxO1 transcription factor in pulmonary hypertension. Nat Med. 2014; 20(11):1289-300. Epub 2014/10/27. doi: 10.1038/nm.3695 PMID: 25344740.

22. El Kasmi KC, Pugliese SC, Riddle SR, Poth JM, Anderson AL, Frid MG, et al. Adventitial fibroblasts induce a distinct proinflammatory/profibrotic macrophage phenotype in pulmonary hypertension. $J$ Immunol. 2014; 193(2):597-609. doi: 10.4049/jimmunol.1303048 PMID: 24928992.

23. McCullagh P, Nelder JA. Generalized linear models. 2nd ed. London; New York: Chapman and Hall; 1989. xix, 511 p.p.

24. Turner H. A peer-reviewed, open-access publication of the R Foundation for Statistical Computing. $\mathrm{R}$ Journal. 2011; 3(2):3-. PMID: WOS:000208590200001.

25. Gardner W, Mulvey EP, Shaw EC. Regression analyses of counts and rates: Poisson, overdispersed Poisson, and negative binomial models. Psychological bulletin. 1995; 118(3):392-404. PMID: 7501743.

26. Bremnes RM, Al-Shibli K, Donnem T, Sirera R, Al-Saad S, Andersen S, et al. The role of tumor-infiltrating immune cells and chronic inflammation at the tumor site on cancer development, progression, and prognosis: emphasis on non-small cell lung cancer. J Thorac Oncol. 2011; 6(4):824-33. doi: 10.1097/ JTO.0b013e3182037b76 PMID: 21173711.

27. Prado-Garcia H, Romero-Garcia S, Aguilar-Cazares D, Meneses-Flores M, Lopez-Gonzalez JS. Tumor-induced CD8+ T-cell dysfunction in lung cancer patients. Clin Dev Immunol. 2012; 2012:741741. doi: 10.1155/2012/741741 PMID: 23118782; PubMed Central PMCID: PMC3483679.

28. Welsh TJ, Green RH, Richardson D, Waller DA, O'Byrne KJ, Bradding P. Macrophage and mast-cell invasion of tumor cell islets confers a marked survival advantage in non-small-cell lung cancer. $\mathrm{J}$ Clin Oncol. 2005; 23(35):8959-67. doi: 10.1200/JC0.2005.01.4910 PMID: 16219934.

29. Zaynagetdinov R, Sherrill TP, Polosukhin VV, Han W, Ausborn JA, McLoed AG, et al. A critical role for macrophages in promotion of urethane-induced lung carcinogenesis. J Immunol. 2011; 187(11):570311. doi: 10.4049/jimmunol.1100558 PMID: 22048774; PubMed Central PMCID: PMC3221921.

30. Chen JJ, Lin YC, Yao PL, Yuan A, Chen HY, Shun CT, et al. Tumor-associated macrophages: the double-edged sword in cancer progression. J Clin Oncol. 2005; 23(5):953-64. doi: 10.1200/JCO.2005.12. 172 PMID: 15598976.

31. Sica A, Mantovani A. Macrophage plasticity and polarization: in vivo veritas. J Clin Invest. 2012; 122 (3):787-95. doi: 10.1172/JCI59643 PMID: 22378047; PubMed Central PMCID: PMC3287223.

32. Ohnuki $\mathrm{H}$, Jiang $\mathrm{K}$, Wang $\mathrm{D}$, Salvucci $\mathrm{O}$, Kwak $\mathrm{H}$, Sanchez-Martin $\mathrm{D}$, et al. Tumor-infiltrating myeloid cells activate DII4/Notch/TGF-beta signaling to drive malignant progression. Cancer Res. 2014; 74 (7):2038-49. doi: 10.1158/0008-5472.CAN-13-3118 PMID: 24520074; PubMed Central PMCID: PMC3985086.

33. Bellocq A, Antoine M, Flahault A, Philippe C, Crestani B, Bernaudin JF, et al. Neutrophil alveolitis in bronchioloalveolar carcinoma: induction by tumor-derived interleukin-8 and relation to clinical outcome. Am J Pathol. 1998; 152(1):83-92. PMID: 9422526; PubMed Central PMCID: PMC1858104.

34. Hume DA. Macrophages as APC and the dendritic cell myth. J Immunol. 2008; 181(9):5829-35. PMID: 18941170.

35. Perrot I, Blanchard D, Freymond N, Isaac S, Guibert B, Pacheco Y, et al. Dendritic cells infiltrating human non-small cell lung cancer are blocked at immature stage. J Immunol. 2007; 178(5):2763-9. PMID: 17312119.

36. de Visser KE, Korets LV, Coussens LM. De novo carcinogenesis promoted by chronic inflammation is B lymphocyte dependent. Cancer Cell. 2005; 7(5):411-23. doi: 10.1016/j.ccr.2005.04.014 PMID: 15894262.

37. Shapiro-Shelef M, Calame K. Regulation of plasma-cell development. Nat Rev Immunol. 2005; 5 (3):230-42. doi: 10.1038/nri1572 PMID: 15738953.

38. Lohr M, Edlund K, Botling J, Hammad S, Hellwig B, Othman A, et al. The prognostic relevance of tumour-infiltrating plasma cells and immunoglobulin kappa $C$ indicates an important role of the humoral 
immune response in non-small cell lung cancer. Cancer Lett. 2013; 333(2):222-8. doi: 10.1016/j. canlet.2013.01.036 PMID: 23370224.

39. Fujimoto M, Yoshizawa A, Sumiyoshi S, Sonobe M, Kobayashi M, Koyanagi I, et al. Stromal plasma cells expressing immunoglobulin G4 subclass in non-small cell lung cancer. Hum Pathol. 2013; 44 (8):1569-76. doi: 10.1016/j.humpath.2013.01.002 PMID: 23465276.

40. Francisco LM, Sage PT, Sharpe AH. The PD-1 pathway in tolerance and autoimmunity. Immunol Rev. 2010; 236:219-42. doi: 10.1111/j.1600-065X.2010.00923.x PMID: 20636820; PubMed Central PMCID: PMC2919275.

41. Patsoukis N, Brown J, Petkova V, Liu F, Li L, Boussiotis VA. Selective effects of PD-1 on Akt and Ras pathways regulate molecular components of the cell cycle and inhibit T cell proliferation. Sci Signal. 2012; 5(230):ra46. doi: 10.1126/scisignal.2002796 PMID: 22740686.

42. Topalian SL, Hodi FS, Brahmer JR, Gettinger SN, Smith DC, McDermott DF, et al. Safety, activity, and immune correlates of anti-PD-1 antibody in cancer. The New England journal of medicine. 2012; 366 (26):2443-54. Epub 2012/06/05. doi: 10.1056/NEJMoa1200690 PMID: 22658127; PubMed Central PMCID: PMC3544539. 